\section{A Call to Action for Optimizing the Electronic Health Record in the Parenteral Nutrition Workflow}

\author{
Vincent W. Vanek, MD, FACS, FASPEN ${ }^{1}$; Phil Ayers, PharmD, BCNSP, FASHP ${ }^{2}$; \\ Michael Kraft, PharmD, BCNSP ${ }^{3}$ iD ; Jean M. Bouche, RD, CD $^{4}$; \\ Van T. Do, PharmD ${ }^{5}$; Charles W. Durham, PharmD, BCPS ${ }^{6}$; Peggi Guenter, PhD, \\ RN, FAAN ${ }^{7}$; Lindsey Hoggle, MS, RDN, PMP ${ }^{8}$; Sue Kent, MS, RDN, LD ${ }^{9}$; \\ Emily T. Lin, PharmD ${ }^{10}$; L. Steven Molinar, RD, LD ${ }^{11}$; Steven W. Plogsted, PharmD, \\ BCNSP, CNSC ${ }^{12}$; Jessica M. Poehls, PharmD, BCPPS ${ }^{13}$; Peggy Turner, MS RD, \\ LD, FAND ${ }^{14}$; Charles Van Way III, MD, FACS, FCCM, FCCP, FASPEN ${ }^{15}$ (iD; \\ and American Society for Parenteral and Enteral Nutrition, Academy of Nutrition and \\ Dietetics, American Society of Health-System Pharmacists
}

Nutrition in Clinical Practice Volume 33 Number 5 October 2018 e1-e21 (c) 2018 American Society of Health-System Pharmacists, Inc., American Society for Parenteral and Enteral Nutrition, and the Academy of Nutrition and Dietetics. All rights reserved. DOI: $10.1002 / \mathrm{ncp} .10095$ wileyonlinelibrary.com

WILEY

\begin{abstract}
Parenteral nutrition (PN) is a complex therapeutic modality provided to neonates, children, and adults for various indications. Surveys have shown that current electronic health record (EHR) systems are in need of functionality enhancement for safe and optimal delivery of PN. This is a consensus statement from the American Society for Parenteral and Enteral Nutrition, the Academy of Nutrition and Dietetics, and the American Society of Health-System Pharmacists outlining some of the key challenges to prescribing, order review/verification, compounding, and administration of PN using EHRs today and is a call to action for clinicians and vendors to optimize their EHRs regarding the PN build and workflow. (Nutr Clin Pract. 2018;33:e1-e21)
\end{abstract}

\title{
Keywords
}

clinical informatics; electronic health record; medication errors; parenteral nutrition; patient safety

\footnotetext{
Linked content: This article is related to this executive summary by Vanek et al.: https://doi.org/10.1002/ncp.10202

From the ${ }^{1}$ St Elizabeth Youngstown Hospital, Youngstown, Ohio, USA; ${ }^{2}$ Mississippi Baptist Medical Center, Jackson, Mississippi, USA; ${ }^{3}$ University of Michigan, Ann Arbor, Michigan, USA; ${ }^{4}$ Option Care Home Infusion, Wauwatosa, Wisconsin, USA; ${ }^{5}$ Oregon Health \& Science University, Portland, Oregon, USA; ${ }^{6}$ Sentara Healthcare, Virginia Beach, Virginia, USA; ${ }^{7}$ American Society for Parenteral and Enteral Nutrition, Silver Spring, Maryland, USA $;{ }^{8}$ Academy of Nutrition and Dietetics, Chicago, Illinois, USA $;{ }^{9}$ Cleveland Clinic, Cleveland, Ohio, USA; ${ }^{10}$ Mayo Clinic, Rochester, Minnesota, USA; ${ }^{11}$ Salem Health, Salem, Oregon, USA; ${ }^{12}$ Nationwide Children's Hospital, Columbus, Ohio, USA; ${ }^{13}$ University of Wisconsin Hospitals and Clinics, Madison, Wisconsin, USA; ${ }^{14}$ University of Oklahoma Health Sciences Center, Oklahoma City, Oklahoma, USA; ${ }^{15}$ University of Missouri, Kansas City, Missouri, USA.
}

This article is being copublished by the American Society of Health-System Pharmacists (ASHP), the Academy of Nutrition and Dietetics (AND), and the American Society for Parenteral and Enteral Nutrition (ASPEN). Minor differences in style may appear in each publication, but the article is substantially the same in each journal.

Financial disclosure: None declared.

Conflicts of interests: None declared.

This article originally appeared online on July 25, 2018.

Podcast available

Listen to a discussion of this manuscript with $N C P$ Editor-in-Chief Jeanette M. Hasse, PhD, RD, LD, FADA, CNSC, and author Vincent W. Vanek, MD, FACS, FASPEN. This and other NCP podcasts are available at: https://onlinelibrary.wiley.com/page/journal/19412452/homepage/ podcasts

Corresponding Author:

Peggi Guenter, PhD, RN, FAAN, FASPEN, Senior Director of Clinical Practice, Quality, and Advocacy, American Society for Parenteral and Enteral Nutrition (ASPEN), 8401 Colesville Road, Suite 510, Silver Spring, MD 20910.

Email: peggig@nutritioncare.org 
Parenteral nutrition (PN) is an important therapy provided to neonates, children, and adults. $\mathrm{PN}$ is a complex medication containing up to 40 different ingredients. ${ }^{1}$ In 2013, PN was administered during approximately 302,000 hospital stays, while many other patients received this therapy in the home or long-term care settings. ${ }^{2}$ The Institute for Safe Medication Practices (ISMP) classifies PN as a high-alert medication and recommends that strategies be formulated to minimize harm and errors in patients receiving this medication. ${ }^{3} \mathrm{PN}$ should only be used in patients in whom the benefit outweighs the potential risks. In 2017, the American Society for Parenteral and Enteral Nutrition (ASPEN) published consensus recommendations on the appropriate use of PN. ${ }^{4}$ A 2013 ASPEN survey with a gap analysis revealed only $58 \%$ of healthcare organizations have precautions in place to prevent errors and patient harm associated with PN. ${ }^{5}$

The PN process most often involves a number of basic steps, including prescribing, order review/verification, compounding, labeling, and administration. ${ }^{6} \mathrm{PN}$ ordering has evolved over the years to include not only physicians as prescribers, but also dietitians, nurse practitioners, pharmacists, and physician assistants. The ASPEN Parenteral Nutrition Safety Consensus Recommendations advised that PN shall be prescribed using standardized electronic orders via a computerized provider order entry (CPOE) system. ${ }^{6}$

In 2015, a work group was formed consisting of members from ASPEN, the Academy of Nutrition and Dietetics (Academy), and the American Society of Health-System Pharmacists (ASHP). This work group consisted of experts in PN, electronic health record (EHR) functionality, and health information technology (HIT) standards. The work group identified areas of opportunity for optimizing the EHR in the PN workflow. The goals of the work group were:

1. increase the awareness of EHR vendors to consensus recommendations and guidelines for safe PN ordering, ${ }^{6,7}$

2. recommend to EHR vendors opportunities to improve $\mathrm{PN}$ process functionality and clinical decision support (CDS),

3. encourage HIT standards for PN across the continuum of care, and

4. publish a joint consensus statement on PN and EHR best practices.

Key areas identified by the work group for this publication were:

1. standardized PN order and label;

2. CDS and warnings for macronutrient and micronutrient dosing, toxicity, and incompatibilities;
3. EHR interfaces, interoperability, and workflows involving automated compounding devices (ACDs) functionality to improve safety and minimize risk of errors;

4. ordering cyclic PN, taper up, and taper down; and

5. transition of PN from hospital to home or other alternative care settings and vice versa.

The work group was divided into 5 subgroups, with each assigned 1 of the above key areas of the consensus statement. Each subgroup reviewed the literature and developed evidence-based recommendations for their respective area. Several members of the work group combined the sections of the subgroups and developed the rough draft of the paper. The paper was then revised based on review of the entire paper by the entire work group. The leaders on the work group from each organization identified appropriate members within their organization to review and submit comments on the final rough draft of the paper. The entire work group discussed and came to consensus on revisions of the paper based on reviewers' comments to form the final draft of the paper. The leaders on the work group from each organization identified and sent the final draft of the paper to the appropriate body within their organization for final review, revision, and approval on behalf of their organization.

\section{Opportunities for Optimizing the EHR in the PN Workflow}

\section{Standardized PN Order and Label}

ASPEN recommends standardization as an errorprevention strategy for creating lasting system changes for the safe use of medications. ${ }^{8}$ A 2013 PN use survey with a gap analysis reported $90 \%$ of organizations used a self-defined standardized PN order form. ${ }^{5}$ This survey also noted only $33 \%$ of those surveyed (298 of 895 ) used a CPOE system for ordering PN. A follow-up survey was performed in 2015, ${ }^{9}$ and $63 \%$ (436 of 689 ) of the respondents replied they were using an electronic method of ordering PN. Additionally, 78\% (341 of 436) of the respondents were using a self-defined standard electronic method of PN ordering, with the others (95 respondents) using a non-standard electronic method.

In 2007, ASPEN published a statement on PN standardization that advocated for a standardized process for PN management to reduce variation and promote uniformity among healthcare organizations and clinicians. ${ }^{8}$ Recommended standard processes for $\mathrm{PN}$ in this statement included: ordering, labeling, nutrition requirements, screening, administration, and monitoring.

The 2004 ASPEN Safe Practices for Parenteral Nutrition and the 2014 ASPEN PN Safety Consensus 
Recommendations supported the use of standardized order formats for PN. ${ }^{6,10}$ The ASPEN PN Safety Consensus Recommendations also supported standardization throughout the PN process. ${ }^{6}$ The PN process included: prescribing and communicating the PN order, PN order review and verification, $\mathrm{PN}$ compounding, and $\mathrm{PN}$ administration. The Agency for Healthcare Research and Quality reported a children's hospital reduced PN errors from an average of 9 per $1000 \mathrm{PN}$ orders in 2004 to approximately 2 per 1000 PN orders in 2011 by adopting a standardized PN ordering and administration process. ${ }^{11}$ The ASPEN PN Safety Consensus Recommendations stated that all PN ingredients shall be ordered as amounts per day for adult patients and amounts per kilogram per day in pediatric and neonatal patients. ${ }^{6}$

PN prescribing and labeling, using an EHR, should follow templates developed by the ASPEN PN Safety Task Force as follows: ${ }^{1,12}$

- Standardized PN ordering templates for adults and pediatric/neonatal patients (Figures 1 and 2, respectively)

- Standardized PN labeling templates for adults and pediatric/neonatal patients (Figures 3 and 4, respectively)

- Standardized injectable lipid emulsions (ILE) labeling templates for adults and pediatric/neonatal patients (Figures 5 and 6, respectively)

- Standardized Home or Alternate care setting PN labeling templates (Figure 7 shows an example for sadult patients)

The templates above should be adopted by clinicians and EHR vendors to bring standardization to the prescribing and labeling of PN.

\section{CDS for Macronutrient and Micronutrient Dosing, Toxicity, and Incompatibilities}

PN is a highly complex medication with multiple individual components including amino acids, dextrose, ILE, electrolytes, minerals, vitamins, trace elements, insulin, and other medications as well as solubilizers, emulsifiers, and preservatives. Given the vast complexity, PN has the potential to cause significant patient harm, especially when errors occur. ${ }^{13,14}$ The PN admixture needs to provide appropriate amounts of macronutrients (amino acids, carbohydrates, and lipids) and micronutrients (electrolytes, minerals, vitamins, and trace elements) for patients requiring PN based on the patient's clinical condition and laboratory status to meet the maintenance needs and prevent malnutrition in well-nourished patients and to treat deficiencies and restore health in malnourished patients (Table 1). At the same time, the PN admixture should not contain total amounts, con- centrations, or rate of infusion of these nutrients that could result in toxicities or make the admixture unstable resulting in particulate matter which may include precipitates being infused into the patient, either of which could cause significant morbidity or mortality (Table 2 ). Recommended daily and maximum doses of macronutrients and micronutrients for neonatal and pediatric patients can be found in Table 3 . Furthermore, the ASPEN clinical guidelines provide some specific metrics for use in CDS. ${ }^{7}$

There are 2 main types of PN admixtures: 2-in-1 (amino acids and dextrose in 1 bag and ILEs given as separate infusion in a different bag), and 3-in-1 (amino acids, dextrose, and ILEs infused together in same bag). When ILEs were first introduced in the United States (U.S.) in the mid-1950s, they were frequently associated with adverse reactions, varying from minor fever to potentially lifethreatening anaphylaxis. As a result, ILEs were removed from the market. ${ }^{20,34}$ When originally developed in the late 1960 s, PN only included amino acids and dextrose (2-in1 admixture). ${ }^{34-36}$ Safer commercial ILEs using different oils were subsequently available but were infused separately from the amino acids and dextrose-based PN admixture. ${ }^{23,37}$

By 1983, the U.S. Food and Drug Administration (FDA) had approved 3-in-1 PN admixtures or total nutrient admixtures (TNA) in which all 3 macronutrients, i.e., amino acids, dextrose, and ILEs, could be included in the same PN bag. ${ }^{20,21}$ The TNA is an oil-in-water emulsion with tenuous thermodynamic stability. Solubilizers improve water solubility and emulsifiers can help prevent water soluble and fat soluble components in the 3-in-1 PN from becoming unstable, causing the formation of coalesced fat particles greater than 5 microns in diameter or separating out the water and fat soluble components ("cracking" the emulsion), either of which could cause severe complications, or even death, if infused into a patient.

Despite the non-nutrient ingredients (emulsifiers and solubilizers), the final concentrations of many of the macronutrients and micronutrients in the 3-in-1 PN admixture need to be kept within certain concentration thresholds to prevent the admixture from destabilizing (Table 2). The fat droplet surface in these emulsions have a net negative charge, causing an electrostatic repulsion that keeps the droplets from aggregating. ${ }^{37}$ Electrolyte cations are positively charged and have the potential to destabilize the emulsion. Monovalent cations (potassium and sodium) are less likely than divalent cations to destabilize the 3-in-1 PN admixture, so they can be increased up to a total of 150 $\mathrm{mEq} / \mathrm{L}$ combined concentration. ${ }^{20,21}$ The divalent cations (calcium and magnesium) are much more likely to destabilize the emulsion, so they need to be limited to $20 \mathrm{mEq} / \mathrm{L}$ combined concentration. ${ }^{20,21}$ Anion electrolytes (acetate, chloride, and phosphate) do not have specific concentration limits for TNAs since they are negatively charged and have little or no effect on emulsion stability. ${ }^{20}$ 


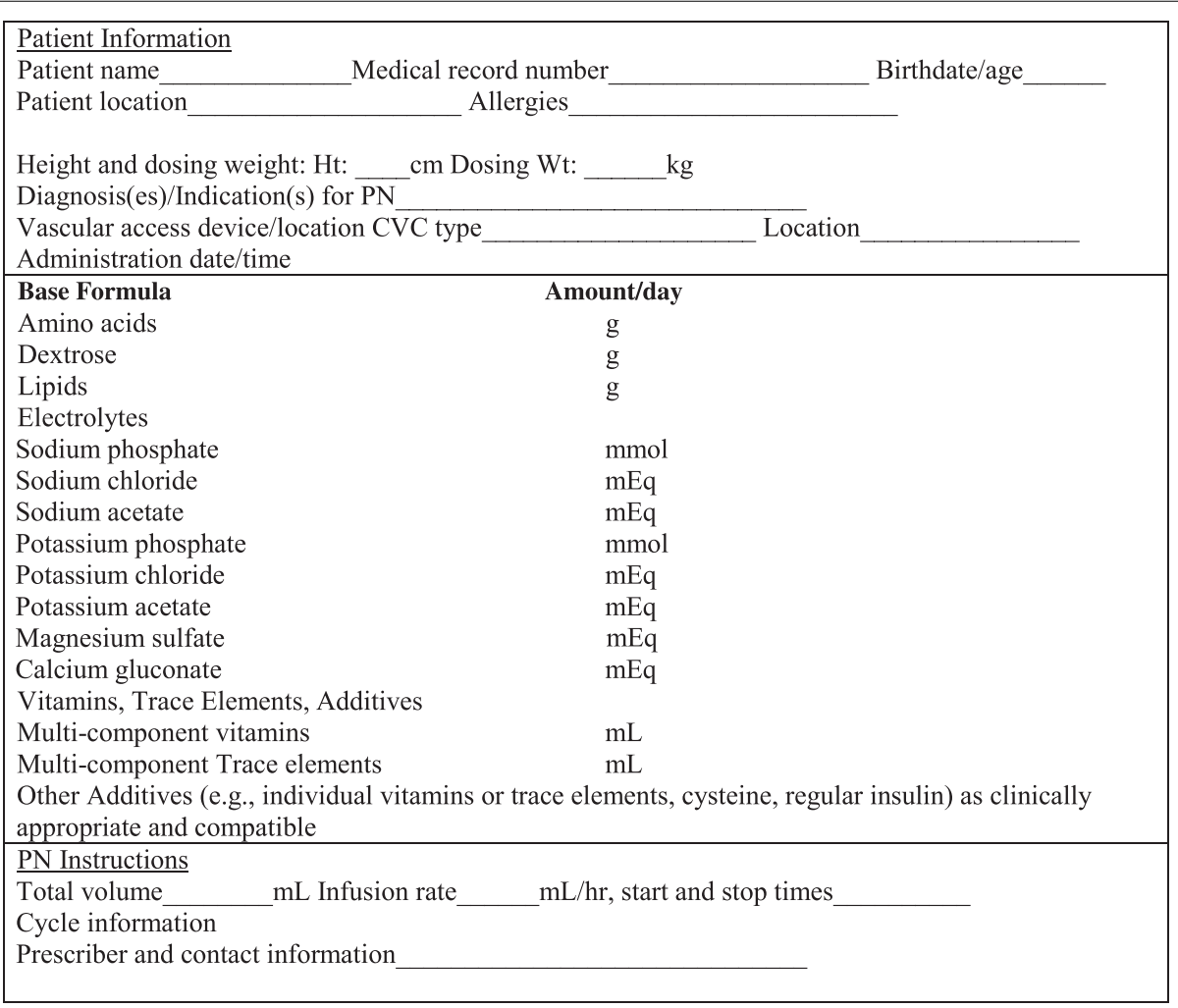

Figure 1. Parenteral Nutrition Order Template: Adult Patient. CVC, central venous catheter; PN, parenteral nutrition. Adapted with permission from Ayers P. ASPEN Parenteral Nutrition Safety Consensus Recommendations. JPEN J Parenter Enteral Nutr. 2014;38(3):296-333. ${ }^{6}$

(C) 2013 American Society for Parenteral and Enteral Nutrition

Calcium and phosphate are relatively insoluble and can precipitate within a PN admixture. Infusion of these precipitates can cause significant morbidity and even mortality. 7,38 The solubility of calcium and phosphate is not only based on the type and final concentrations of calcium and phosphate in the PN admixture but also varies based on the final concentration and distribution of amino acids, final concentration of dextrose, final concentration of magnesium, temperature at which PN is stored and administered, the final $\mathrm{pH}$ of the $\mathrm{PN}$ admixture, other components within the PN admixture, and the sequence in which the components are added to the PN admixture. ${ }^{7,38}$ Keeping the final concentrations of calcium and phosphate at or below $8 \mathrm{mEq} / \mathrm{L}$ and $15 \mathrm{mmol} / \mathrm{L}$, respectively, generally should prevent calcium phosphate precipitation (Table 2). However, this final concentration limit for phosphate is relatively conservative and could be set higher, but the final concentration limits for phosphate and calcium need to be based on the calcium phosphate solubility curves specific to the PN components being used. EHRs should have the functionality of integrating the appropriate calcium phosphate solubility curves into their CDS alerts.

EHRs should provide active real-time CDS alerts to prescribers at the time of order entry to ensure adequate

provision of nutrients to avoid deficiencies and to prevent administering too high of a daily dose, final concentration, or rate of infusion of nutrients that could result in toxicity to the patient or instability of the PN admixture, causing complications or even death. As a safety net, the EHR should also provide CDS to pharmacists at the time of PN order verification and compounding and to nurses at the time of $\mathrm{PN}$ administration to avoid the above adverse outcomes. Also, the PN admixture should be included on the electronic medication administration record (MAR).

\section{EHR Interfaces, Interoperability, and Workflows Involving ACDs - Functionality to Improve Safety and Minimize Risk of Errors}

ACDs should be fully integrated with EHR systems to eliminate any manual transcription, including handwritten, verbal, or fax transmission, in the $P N$ workflow. There are a variety of different types of interfaces. The interface for PN orders should be a direct "automatic" interface that does not require any manual action by a user to transmit or download. Furthermore, PN orders should be retrieved 


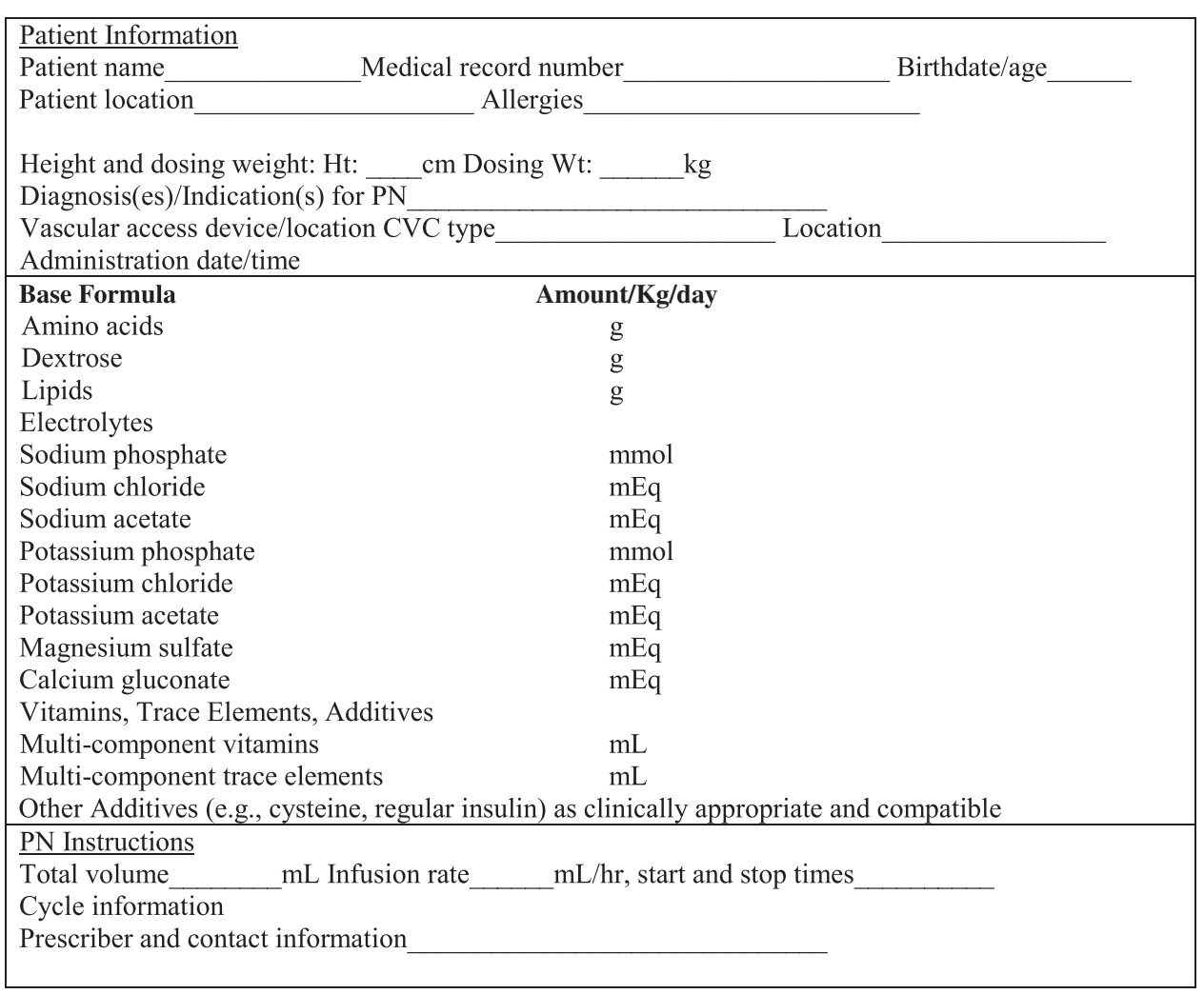

Figure 2. Parenteral Nutrition Order Template: Pediatric/Neonatal Patient. CVC, central venous catheter; PN, parenteral nutrition.

Adapted with permission from Ayers P. ASPEN Parenteral Nutrition Safety Consensus Recommendations. JPEN J Parenter Enteral Nutr. 2014;38(3):296-333. ${ }^{6}$

(C) 2013 American Society for Parenteral and Enteral Nutrition

in the ACD by scanning the PN label barcode (preferred method), by using 2 patient identifiers (e.g., patient name and date of birth), or by order ID number.

The ASPEN PN Safety Consensus Recommendations ${ }^{6}$ define "fully integrated" as the PN order entered into the EHR system being transmitted electronically to the ACD without requiring re-entry of any data, and any modifications to a PN order are electronically transmitted back to the EHR system for prescriber approval and signature. This avoids errors associated with manual transcription, which has been reported as the most common cause for errors in the PN process. ${ }^{39-41}$ The ASHP Guidelines for the Safe Use of Automated Compounding Devices for Preparation of PN Admixtures states that ACDs and ACD software should alert when formulation issues are identified, provide useful clinical information, integrate with existing pharmacy programs, and meet the standards of ASPEN for PN label formats. ${ }^{42}$

Sacks et al conducted a prospective, observational study on the frequency of errors in the PN process at a large university teaching hospital. ${ }^{39} \mathrm{PN}$ errors were classified as being related to prescribing, transcription, preparation, or administration, and they categorized the severity of harm associated with the errors. During an 18-month period, an overall error rate of $1.6 \%$ was observed, and the most common error was related to transcription $(39 \%)$, which included re-entry of PN orders into the ACD. Bonnabry et al completed a systematic risk analysis on their pediatric PN prescribing and preparation processes after implementing several changes, including the elimination of manual transcription. ${ }^{40}$ The greatest risk reduction identified was in the elimination of transcription, followed by problems reading the prescription. Both errors can be eliminated by using standardized electronic orders and implementing fully integrated systems that do not require manual transcription. One retrospective cross-sectional study evaluating the impact of an interactive computerized PN worksheet (outside of the EHR system) on PN prescribing errors demonstrated a reduction in prescribing error rate. ${ }^{41}$ However, separate entry and transcription of the PN order was still required, and the errors that occurred were due to transcription or data entry mistakes. 


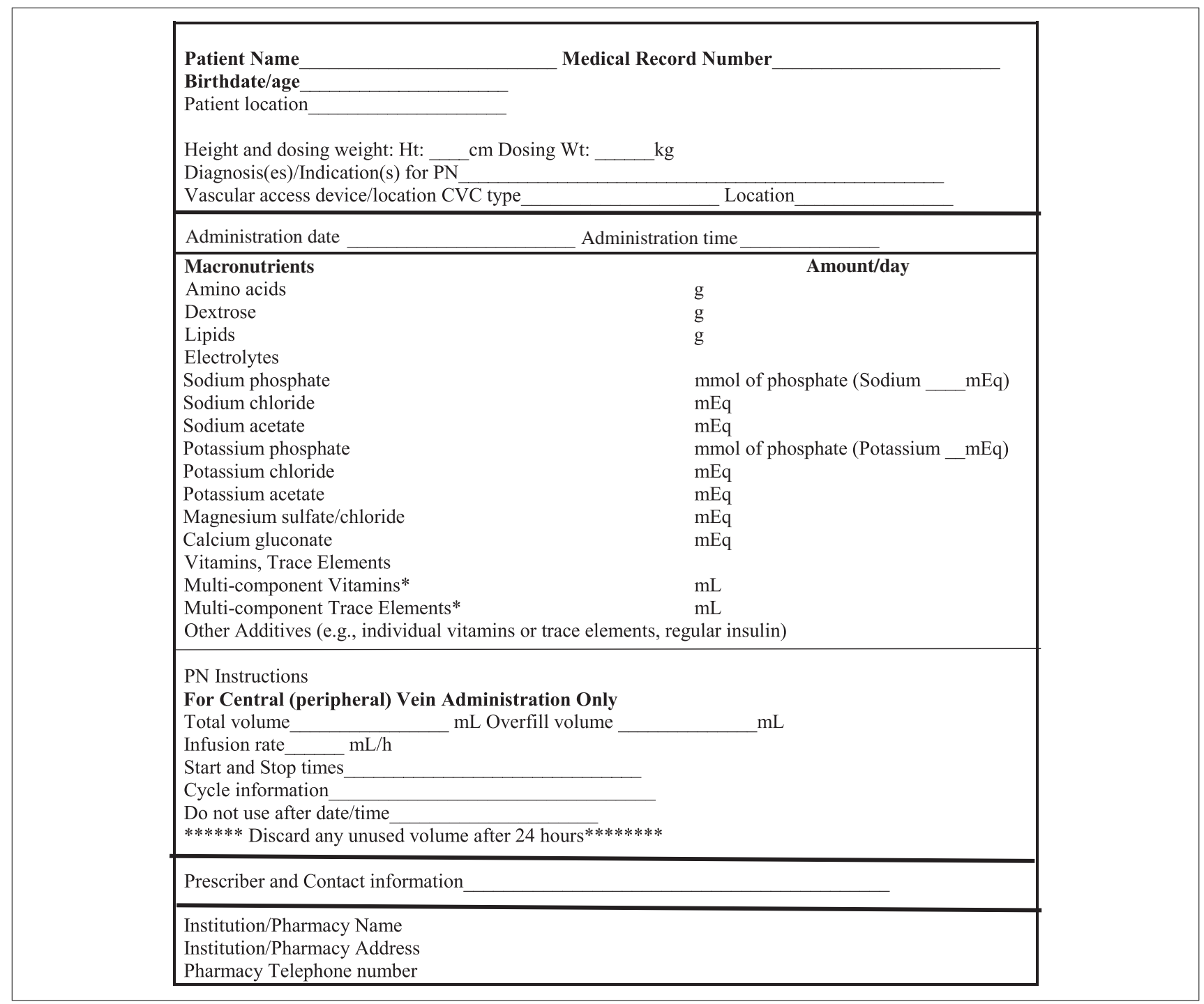

Figure 3. Parenteral Nutrition Label Template: Adult Patient. CVC, central venous catheter; PN, parenteral nutrition. *Specify product name

Adapted with permission from Ayers P. ASPEN Parenteral Nutrition Safety Consensus Recommendations. JPEN J Parenter Enteral Nutr. 2014;38(3):296-333. ${ }^{6}$

(C) 2013 American Society for Parenteral and Enteral Nutrition

A more recent study by MacKay et al in 2016 described the frequency and severity of PN errors at a large academic pediatric hospital after implementing electronic PN ordering and compounding, and this included eliminating transcription. ${ }^{43}$ During a 7-year period, the frequency of PN errors was $0.27 \%$, compared with an error rate of $1.6 \%$ reported by Sacks et al. ${ }^{39}$ In addition, $95 \%$ of errors were associated with administration, and there were no errors associated with transcription. ${ }^{43}$ These data suggest that eliminating manual transcription can significantly reduce errors associated with the PN use process. This also allows the reviewing pharmacist to focus on evaluating the PN order for both clinical and formulation considerations.
One area of concern is maintaining the security of electronic systems and confidentiality of protected health information (PHI). Hilmas and Peoples described their PN process and pharmacist intervention rate. ${ }^{44}$ They did not build an interface between their EHR and ACD, citing concerns about the integrity of data in their EHR by allowing access from an outside vendor. Outside vendors of ACD software should adhere to the local facility policy on patient matching and PHI security. Security of electronic systems is a primary concern, and EHR and ACD vendors should update and use the most secure methods for data transmission and storage. 


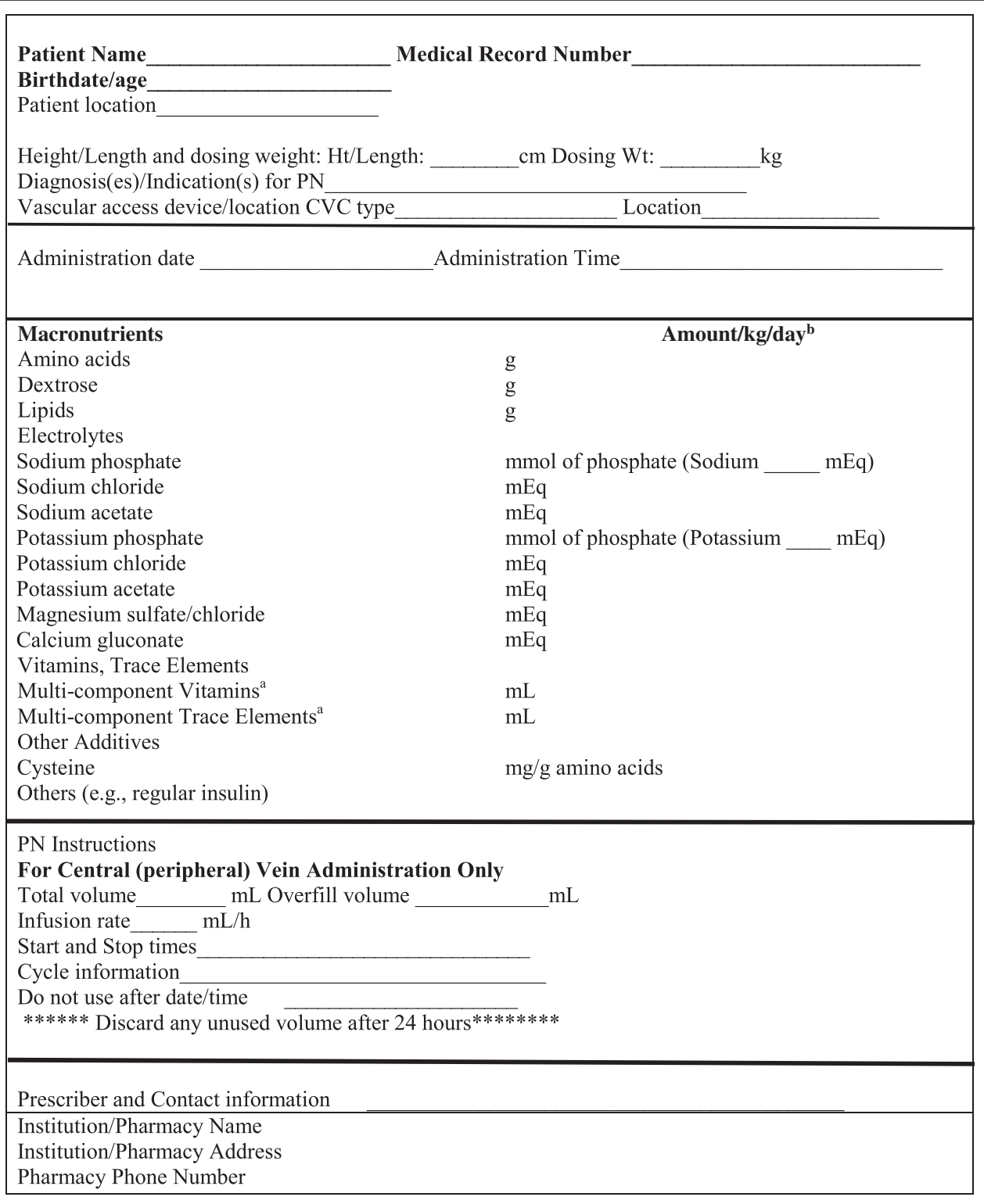

Figure 4. Parenteral Nutrition Label Template: Pediatric/Neonatal Patient. CVC, central venous catheter; PN, parenteral nutrition.

a Specify product name

b Since the admixture usually contains multiple sources of sodium, potassium, chloride, acetate, and phosphorus, the amount of each electrolyte/kg provided by the PN admixture is determined by adding the amount of electrolyte provided by each salt. Adapted with permission from Ayers P. ASPEN Parenteral Nutrition Safety Consensus Recommendations. JPEN J Parenter Enteral Nutr. 2014;38(3):296-333. ${ }^{6}$

(C) 2013 American Society for Parenteral and Enteral Nutrition

There should be a standardized additive sequence in ACDs to optimize safety. The sequence of ingredients on $\mathrm{PN}$ admixture should match between the EHR, the ACD, and the PN label. The calculated total ingredients from ordered units of measure should be listed in matching units on the EHR, ACD, and PN label and should not require any calculation, conversion, or manipulation. These templates and calculations should be configurable for specific patient populations.

Standardized PN order formats designed with ingredients listed in the same sequence may improve consistency and potentially decrease the risk of errors, especially when transitioning care. ${ }^{6,10}$ A children's hospital adopted a standardized ordering and administration process for $\mathrm{PN}$ and 


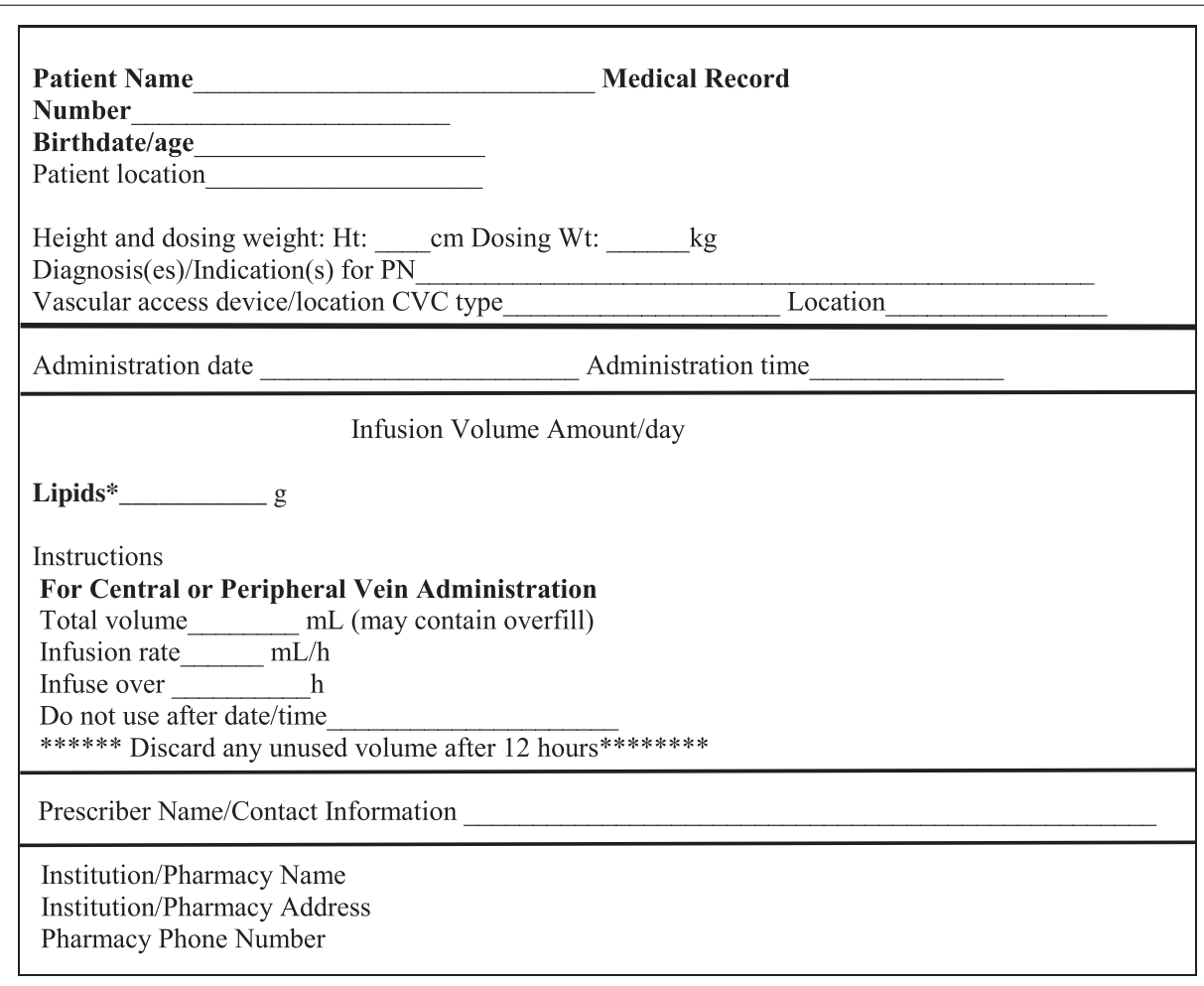

Figure 5. Standard Injectable Lipid Emulsion Label Template: Adult. CVC, central venous catheter; PN, parenteral nutrition. *Specify product name

Adapted with permission from Ayers P. ASPEN Parenteral Nutrition Safety Consensus Recommendations. JPEN J Parenter Enteral Nutr. 2014;38(3):296-333. ${ }^{6}$

(C) 2013 American Society for Parenteral and Enteral Nutrition

demonstrated a reduction in the average number of PNrelated errors in 2004 compared with 2011 (from 9 to 2 per 1000 PN orders). ${ }^{11}$

The ISMP has described several self-reported cases of PN-related errors, some that were near misses (i.e., potential for significant harm or death which fortunately did not occur) and others that have resulted in death. One ISMP report involved a premature infant weighing less than $1 \mathrm{~kg}$ who died after receiving PN with 60 times more sodium than prescribed. ${ }^{45}$ There were several points of failure in this example:

- The prescriber ordered $14.7 \mathrm{mEq}$ of sodium chloride and $982 \mathrm{mg}$ of calcium in the PN prescription.

- The pharmacy technician had to transcribe the prescription into the ACD and inadvertently entered the dose for calcium (982 mg) into the field for sodium chloride (in $\mathrm{mEq}$ ). This resulted in $982 \mathrm{mEq}$ of sodium chloride being compounded in the PN admixture.

- The technician affixed the label from the ACD to the PN admixture (with the incorrect sodium dose), but the pharmacist failed to identify the error.
- A different label with the amounts from the original prescription (listing $14.7 \mathrm{mEq}$ of sodium chloride) was placed over the label from the ACD, and the error was therefore unidentifiable by the nurse.

This series of tragic errors, i.e., prescribing, transcription, labeling, and dispensing errors, highlights the need to fully integrate EHR systems with ACDs, avoid manual transcription of PN orders, optimize and utilize CDS, and match PN prescribing templates with PN templates in ACDs and on PN labels.

Another case reported to ISMP was a 16-year-old boy who received a $\mathrm{PN}$ admixture in which the ingredients were ordered in amounts per $\mathrm{kg}$, but the PN order was manually transcribed to amounts per day. ${ }^{46}$ This resulted in an infusion of a hypo-osmolar PN admixture (138 $\mathrm{mOsm} / \mathrm{L}$ ) with very low doses of nutrients (i.e., amounts in $\mathrm{g} /$ day rather than $\mathrm{g} / \mathrm{kg} /$ day) for almost an entire day before it was identified. Fortunately, no adverse effects were incurred by the patient. There were multiple failures across the entire medication use process in this scenario. For example, the PN order template in the EHR system did not match the template in the pharmacy system and the 


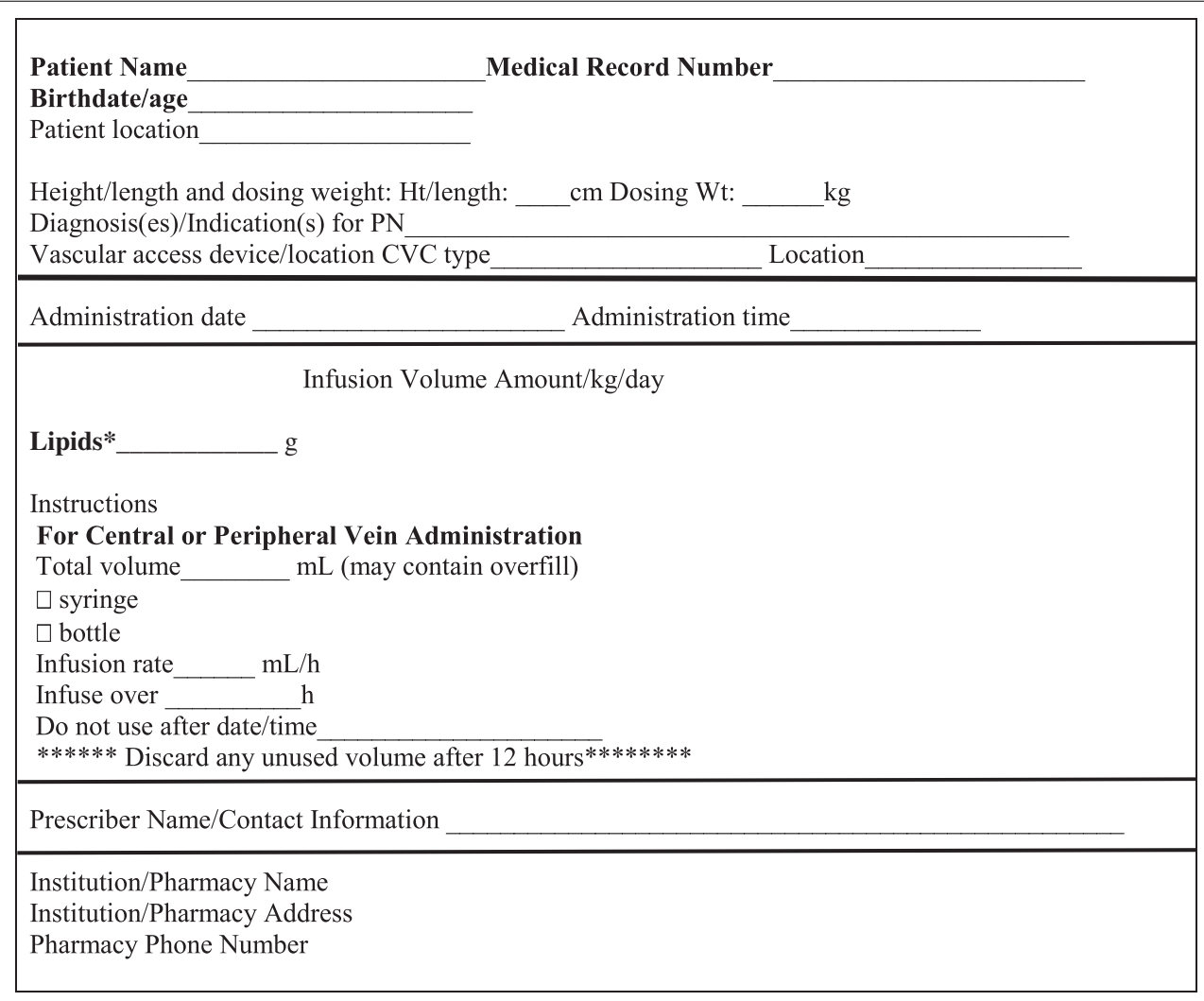

Figure 6. Standard Injectable Lipid Emulsion Label Template: Neonate or Pediatric Patient. CVC, central venous catheter; PN, parenteral nutrition.

${ }^{*}$ Specify product name

Adapted with permission from Ayers P. ASPEN Parenteral Nutrition Safety Consensus Recommendations. JPEN J Parenter Enteral Nutr. 2014;38(3):296-333. ${ }^{6}$

(c) 2013 American Society for Parenteral and Enteral Nutrition

ACD. Furthermore, there was a lack of CDS and automated warnings in both the EHR PN order template and the ACD, a lack of redundancies in the process, and multiple points of transcription.

ISMP has provided several safe practice recommendations, in part based upon these and other reported errors: ${ }^{45,46}$

- Match prescribing and pharmacy templates

- Build, test, and heed automated warnings

- Heighten suspicions of errors

- Integrate effective redundancies

- Provide clear labeling that matches the sequence of ingredients in the PN order templates in the EHR PN order form or CPOE system and the ACD

- Educate and validate competency of all clinicians involved in the $\mathrm{PN}$ process

- Eliminate manual transcription of PN orders

Total calculated ingredients in the PN bag should be displayed and available for viewing on the EHR and ACD to support prepared admixture checking between multiple systems. Calculations between the systems, furthermore, should allow for rounding to a specified decimal place supported by the EHR and ACD.

EHR systems, ACDs, and their interfaces should be simultaneously modifiable, with appropriate review and verification from the pharmacist, to change individual product ingredients to reflect availability, shortages, conservation, etc. and to prevent ordering unavailable products. Medication shortages have significantly impacted patients, healthcare professionals, and health systems during the past several years. The U.S. FDA reported 251 shortages (183 injectables) in 2011, compared with approximately 61 shortages in $2005 .{ }^{47}$ They have worked with stakeholders to implement measures to avoid or prevent medication shortages, as well as improve communication from manufacturers regarding shortages. FDA's First Annual Report on Drug Shortages for Calendar Year 2013 noted that medication shortages continue to pose a challenge to public health, particularly 


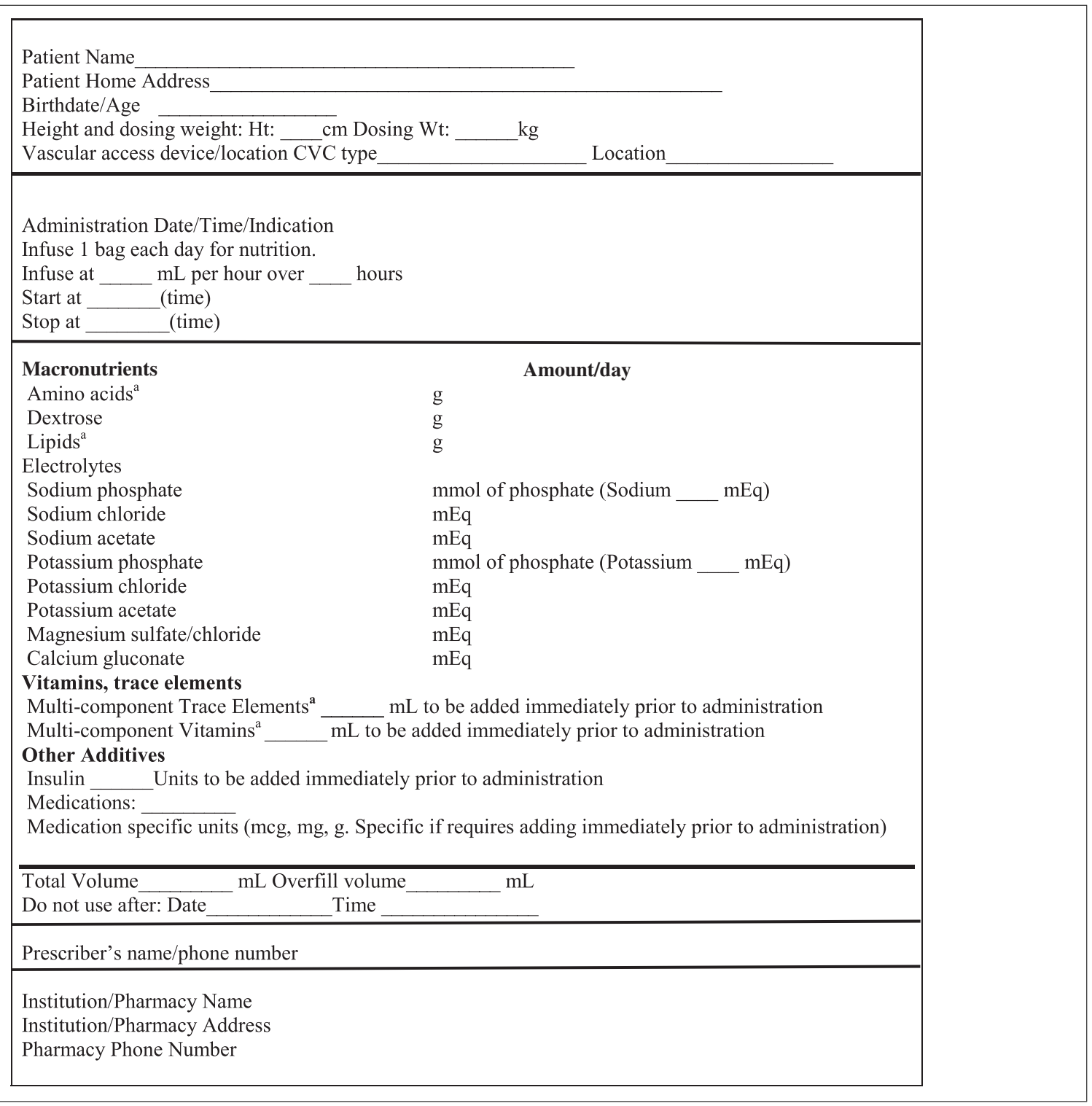

Figure 7. Standard Home PN Label Template: Adult Patient (as an example). CVC, central venous catheter; PN, parenteral nutrition.

a Specify product name

Adapted with permission from Ayers P. ASPEN Parenteral Nutrition Safety Consensus Recommendations. JPEN J Parenter Enteral Nutr. 2014;38(3):296-333. ${ }^{6}$

(C) 2013 American Society for Parenteral and Enteral Nutrition

when they involve a "critical drug," such as those used to provide PN to patients. ${ }^{47}$ These efforts have contributed to a significant reduction in shortages, with the 2015 FDA report showing only 26 total, including 15 injectable medication shortages as well as prevention of a significant number of shortages (142 of which 92 were injectables). ${ }^{48}$ There have been several very serious and tragic outcomes, including patient deaths, as a result of PN-related shortages, including contamination of compounded amino acid products during an amino acid shortage, ${ }^{49}$ selenium deficiency in pediatric patients with intestinal failure, ${ }^{50}$ and anemia and leukopenia in patients receiving long-term PN. ${ }^{51}$ Mainstream media have also highlighted the devastating effects of PN-related shortages on patients, especially in children (e.g., "Children are Dying" article in The Washingtonian in 2013). ${ }^{52}$ Of the 683 respondents to an ASPEN survey, PN-related medication shortages interfered with the ability to meet patient micronutrient $(70 \%$ of respondents) or macronutrient $(47 \%$ respondents) needs, and directly affected patient outcome (16\% respondents). ${ }^{5}$ 
Table 1. General Recommendations for Adult Daily Doses of Macronutrients and Micronutrients in a Parenteral Nutrition Admixture. ${ }^{\mathrm{a}}$

1. Amino Acids -

$\sqrt{ }$ 0.8-2.5 g/kg/day (varies depending if patient normally nourished and using for maintenance therapy, malnourished and using for repletion therapy, or critically ill and using for metabolic support $)^{1,15}$

$\sqrt{ }$ Approximately $20 \%$ of total energy $(\mathrm{kcal} / \mathrm{d})^{16}$

2. Dextrose - approximately $50 \%$ of total energy (kcal/d) and about $60 \%-70 \%$ of non-protein energy (kcals $/$ day $)^{16}$

3. Fatty Acids -

$\sqrt{ }$ Provide at least $2 \%-4 \%$ of total energy intake as linoleic acid and $0.25 \%-0.5 \%$ as alpha linolenic acid to prevent essential fatty acid deficiency ${ }^{17}$

$\sqrt{ }$ Can provide fatty acids as 30\% of total energy (kcal/day) and about $30 \%-40 \%$ of non-protein energy/day as alternative non-protein energy source to dextrose ${ }^{15,16}$

4. Total Energy Requirements - 20-30 kcal/kg/day (depending if used for maintenance, repletion, or metabolic support therapy) $)^{1,16}$

5. Fluid Requirements $-30-40 \mathrm{~mL} / \mathrm{kg} / \mathrm{day}$ (varies based on patient's fluid status, fluid needs, and co-morbidities) ${ }^{1}$

6. Minerals -

$\sqrt{ }$ Calcium $-10-15 \mathrm{mEq} / \mathrm{day}^{1}$

$\sqrt{ }$ Magnesium - 8-20 mEq/day ${ }^{1}$

$\sqrt{ }$ Phosphorus - 20-40 $\mathrm{mmol} / \mathrm{day}^{1}$

7. Electrolytes -

$\sqrt{ }$ Sodium $-1-2 \mathrm{mEq} / \mathrm{kg} / \mathrm{day}^{1}$

$\sqrt{ }$ Potassium $-1-2 \mathrm{mEq} / \mathrm{kg} /$ day $^{1}$

$\sqrt{ }$ Acetate - as needed to maintain normal acid-base balance ${ }^{1}$

$\sqrt{ }$ Chloride - as needed to maintain normal acid-base balance ${ }^{1}$

8. Vitamins - should include daily dose $\mathrm{s}^{13,15}$ and are usually provided by parenteral multivitamin products, although some vitamins are available as individual parenteral products. Recommended daily parenteral doses: ${ }^{18}$

$\sqrt{ }$ Fat-Soluble Vitamins

- Vitamin A - $990 \mathrm{mcg}$ or 3300 IU

- Vitamin D - 5 mcg or 200 IU (some patients may need higher doses)

- Vitamin E - $10 \mathrm{mg}$ or $10 \mathrm{IU}$

- Vitamin K - $150 \mathrm{mcg}$

$\sqrt{ }$ Water-Soluble Vitamins

- Vitamin $B_{1}$ (thiamin) $-6 \mathrm{mg}$

- Vitamin $B_{2}$ (riboflavin) - $3.6 \mathrm{mg}$

- Vitamin $B_{3}$ (niacin) - $40 \mathrm{mg}$

- Vitamin $B_{5}$ (pantothenic acid) - $15 \mathrm{mg}$

- Vitamin $B_{6}$ (pyridoxine) - $6 \mathrm{mg}$

- Vitamin $\mathrm{B}_{12}$ (cyanocobalamin) - $5 \mathrm{mcg}$

- Vitamin C (ascorbic acid) - $200 \mathrm{mg}$

- Folate $-600 \mathrm{mcg}$

- Biotin - $60 \mathrm{mcg}$

9. Trace Elements (TE) - should include daily doses ${ }^{15,16}$ and usually provided by parenteral multi-TE products, although many TE are available as individual parenteral TE products. Recommended daily parenteral doses are currently in flux (see ASPEN position papers ${ }^{18,19}$ ).

${ }^{a}$ These recommendations are not intended to supersede the judgment of the healthcare professional based on the circumstances of the individual patient.

ISMP conducted a survey of more than 1800 healthcare professionals (68\% of which were pharmacists) in $2010 .{ }^{53}$ This survey focused on medication shortages and was disseminated near the peak in medication shortages in 2011. While the survey was not specific to PN-related shortages, the results were nevertheless alarming. Approximately 35\% of respondents reported a near miss (over 1000 near misses reported), approximately $25 \%$ reported an error, and about $20 \%$ reported an adverse patient outcome. Many of these included medications that were high alert or considered essential and life-saving with no suitable alternatives, including PN-related products such as intravenous (IV) electrolytes and ILEs. There was also significant frustration regarding shortages, including little or no information about the duration of a shortage $(85 \%)$, the lack of advanced warning of a shortage (84\%), and substantial resources spent investigating and developing a plan of action. ${ }^{53}$

ISMP conducted another survey on PN-related shortages in 2014 and included 234 healthcare professionals $\left(81 \%\right.$ of which were pharmacists). ${ }^{54} \mathrm{Up}$ to $28 \%$ of respondents reported a medication error related to the 
Table 2. Adult Limits for Daily Dose, Final Concentration, or Infusion Rates for Macronutrients and Micronutrients for 2-in-1 (Dextrose and Amino Acids Only) and 3-in-1 (Dextrose, Amino Acids, and Lipid Emulsion Altogether) Parenteral Nutrition Admixtures to Prevent Toxicities or Solubility Incompatibilities. ${ }^{\text {a }}$

1. Amino Acids -

$\sqrt{ }$ Final Concentration Limits -

- 2-in-1 PN - no specific limits

- 3-in-1 PN - should be greater than or equal to $4 \%$ to avoid destabilizing the admixture ${ }^{7,20,21}$

$\sqrt{ }$ Daily Dose - no specific limits

$\sqrt{ }$ Infusion Rates - no specific limits

2. Dextrose -

$\sqrt{ }$ Final Concentration Limits -

- 2-in-1 PN - no specific limits

- 3 -in-1 PN - should be greater than or equal to $10 \%$ to avoid destabilizing the emulsion ${ }^{7,20,21}$

$\sqrt{ }$ Daily Dose - no specific limits

$\sqrt{ }$ Infusion Rates - generally less than or equal to $4 \mathrm{mg} / \mathrm{kg} / \mathrm{min}$ for critically ill patients and less than or equal to 7 $\mathrm{mg} / \mathrm{kg} / \mathrm{min}$ in stable patients, ${ }^{1}$ but infusion rates need to be based on patient's individual needs and co-morbidities

$\sqrt{ }$ Maintain blood glucose levels less than or equal to $180 \mathrm{mg} / \mathrm{dL}^{1}$

3. Fatty Acids -

$\sqrt{ }$ Final Concentration Limits -

- 2-in-1 PN - not applicable (infused separately from PN admixtures with available products of $10 \%$ or $20 \%$ ILEs) ${ }^{17}$

- 3 -in-1 PN - should be greater than or equal to $2 \%$ to avoid destabilizing the emulsion ${ }^{7,20,21}$

$\sqrt{ }$ Daily Dose -

- should not exceed $60 \%$ of total energy or $2.5 \mathrm{~g} / \mathrm{kg} / \mathrm{day}^{17}$

$\sqrt{ }$ Infusion Rates - should be administered at a rate less than or equal to $0.11 \mathrm{~g} / \mathrm{kg} / \mathrm{hr}$ to avoid overload of the reticuloendothelial system, which can cause pulmonary, hepatic, and platelet dysfunction; ${ }^{10,21-23}$ to minimize the risk of infection, individual ILE containers should not hang any longer than 12 hours, while ILE within 3-in-1 PN can hang up to 24 hours a day. ${ }^{10,21}$

4. Mineral

$\sqrt{ }$ Maintain serum triglyceride levels less than or equal to $400 \mathrm{mg} / \mathrm{dL}^{1}$

$\sqrt{ }$ Calcium $^{b}$ - final concentration of calcium is limited by calcium/phosphorus stability curve, but a safe limit is $8 \mathrm{mEq} / \mathrm{L}$; to avoid instability for 3-in-1 PN admixtures, the final concentration of the combination of magnesium and calcium should not exceed $20 \mathrm{mEq} / \mathrm{L} .^{20,21}$

$\sqrt{ }$ Phosphorus $^{\mathrm{b}}$ - a safe final concentration is $15 \mathrm{mmol} / \mathrm{L}$, but higher limits could be administered based on the calcium/phosphorus solubility curves for the PN components being used. ${ }^{20,24}$

$\sqrt{ }$ Magnesium - final concentration of the combination of magnesium and calcium should not exceed $20 \mathrm{mEq} / \mathrm{L}$ to avoid instability in 3-in-1 PN admixtures. ${ }^{20,21}$

5. Electrolytes ${ }^{\mathrm{a}}$

$\sqrt{ }$ Potassium -

- Final Concentration - should not exceed $100 \mathrm{mEq} / \mathrm{L}^{25,26}$

- Rate:

- Not on cardiac monitor - should not exceed $10 \mathrm{mEq} / \mathrm{hr}^{26}$

- On cardiac monitor - should not exceed $20 \mathrm{mEq} / \mathrm{hr}^{26}$

$\sqrt{ }$ Sodium - final concentrations of potassium and sodium combined should not exceed $150 \mathrm{mEq} / \mathrm{L}$ to avoid instability of 3-in-1 PN admixtures; ${ }^{20,21}$ while there are no specific limits for 2-in-1 admixtures, exceeding $154 \mathrm{mEq} / \mathrm{L}$ of sodium will result in a hypertonic admixture and should be avoided.

$\sqrt{ }$ Acetate - no specific limit

$\sqrt{ }$ Chloride - no specific limit

6. Vitamins and Trace Elements - see Table 1

7. Osmolarity - no specific limits if administered via central venous catheter but should be less than or equal to $900 \mathrm{mOsm} / \mathrm{L}$ if administered via peripheral vein ${ }^{7,15,26,27}$

\footnotetext{
${ }^{\text {a }}$ These recommendations are not intended to supersede the judgment of the healthcare professional based on the circumstances of the individual patient.

${ }^{b}$ Final concentrations of minerals and electrolytes for stability regarding calcium phosphorus precipitation and stability of 3-in-1 admixtures vary depending on the amino acid solution and other PN components used, so all manufacturer's recommendations regarding limits on final concentrations of mineral and electrolyte concentrations in PN admixtures should be checked.

PN, parenteral nutrition; ILEs, injectable lipid emulsions.
} 
Table 3. Recommended Neonatal and Pediatric Daily and Maximum Doses of Macronutrients and Micronutrients in Parenteral Nutrition Admixtures. ${ }^{a}$

1. Amino Acids 28,29

$\sqrt{ }$ Protein intake should be between $10 \%-20 \%$ of the total energy in children

$\sqrt{ }$ Premature infant $-1-3 \mathrm{~g} / \mathrm{kg} /$ day (maximum 3-4 g/kg/day)

$\sqrt{ }$ Younger than 1 year of age $-1-2 \mathrm{~g} / \mathrm{kg} /$ day (maximum $3 \mathrm{~g} / \mathrm{kg} /$ day)

$\sqrt{ }$ 1-10 years of age $-1-2 \mathrm{~g} / \mathrm{kg} /$ day (maximum $1.5-3 \mathrm{~g} / \mathrm{kg} /$ day)

$\sqrt{ }$ Older than 10 years of age (adolescents) $-1 \mathrm{~g} / \mathrm{kg} /$ day (maximum $2.5 \mathrm{~g} / \mathrm{kg} / \mathrm{day}$ )

2. Total Energy Requirements ${ }^{28}$

$\sqrt{ }$ Premature infant $-120-150 \mathrm{kcal} / \mathrm{kg} /$ day

$\sqrt{ }$ Younger than 6 months of age $-90-129 \mathrm{kcal} / \mathrm{kg} /$ day

$\sqrt{ }$ 6-12 months of age $-80-100 \mathrm{kcal} / \mathrm{kg} /$ day

$\sqrt{ } 1-7$ years of age $-75-90 \mathrm{kcal} / \mathrm{kg} /$ day

$\sqrt{ } 7-12$ years of age $-60-75 \mathrm{kcal} / \mathrm{kg} /$ day

$\sqrt{ } 12-18$ years of age $-30-60 \mathrm{kcal} / \mathrm{kg} /$ day

3. Dextrose 28,29

$\sqrt{ }$ Carbohydrate intake should be between $50 \%-60 \%$ of the total energy for children

Dextrose Requirements

\begin{tabular}{lc}
\hline Age Group & Dextrose \\
\hline Younger than 1 year & Initial: $6-8 \mathrm{mg} / \mathrm{kg} / \mathrm{min}$ \\
& Goal: $10-14 \mathrm{mg} / \mathrm{kg} / \mathrm{min}$ \\
$\mathrm{Maximum}: 14-18 \mathrm{mg} / \mathrm{kg} / \mathrm{min}$
\end{tabular}

4. Fatty Acids 28,30

$\sqrt{ }$ Fat intake should provide between $20 \%-30 \%$ of the total energy (may be higher with peripheral PN)

$\sqrt{ }$ Maximum infusion rate should not exceed $0.15 \mathrm{~g} / \mathrm{kg} / \mathrm{hr}$

$\sqrt{ }$ Minimum dose needed to prevent the development of an essential fatty acid deficiency (EFAD) depends on the fatty acid source of the lipid being used. In the older patient providing at least $2 \%-4 \%$ of the energy requirements from linoleic acid and $0.25 \%-0.5 \%$ of the energy requirements from alpha linoleic is needed to prevent the development of EFAD. Preterm infants should receive a minimum of $0.25 \mathrm{~g} / \mathrm{kg}$ lineoleic acid, whereas the term and older infants should receive at least $0.1 \mathrm{~g} / \mathrm{kg}$ linoleic acid.

Fat Requirements

\begin{tabular}{lc}
\hline Age Group & Lipids \\
\hline Younger than 1 year & Initial: $1-2 \mathrm{~g} / \mathrm{kg}$ \\
& Maximum: $3 \mathrm{~g} / \mathrm{kg}$ \\
$1-10$ years & Initial: $1-2 \mathrm{~g} / \mathrm{kg}$ \\
& Maximum: $2-25 \mathrm{~g} / \mathrm{kg}$ \\
Older than 10 years & Initial: $1 \mathrm{~g} / \mathrm{kg}$ \\
& Maximum: $1-2 \mathrm{~g} / \mathrm{kg}$
\end{tabular}


Table 3. Continued.

5. Fluid Requirements ${ }^{31}$

Daily Fluid Maintenance Requirement for Pediatrics

\begin{tabular}{ll}
\hline Body Weight & Amount of Fluid per Day \\
\hline Less than or equal to $10 \mathrm{~kg}$ & $100 \mathrm{~mL} / \mathrm{kg}$ \\
Greater than $10 \mathrm{~kg}$ and less than or equal to $20 \mathrm{~kg}$ & $1000 \mathrm{~mL}+50 \mathrm{~mL} / \mathrm{kg} \mathrm{over} 10 \mathrm{~kg}$ \\
Greater than $20 \mathrm{~kg}$ & $1500 \mathrm{~mL}+20 \mathrm{~mL} / \mathrm{kg}$ over $20 \mathrm{~kg}$ \\
\hline
\end{tabular}

6. Minerals ${ }^{28,32}$

\begin{tabular}{|c|c|c|c|c|c|}
\hline & Neonates & 1 month-1 year & $1-3$ years & $4-10$ years & $\begin{array}{c}\text { Older than } 10 \\
\text { years }\end{array}$ \\
\hline Calcium, mEq/kg/day & $2-3$ & $0.6-1$ & 0.5 & 0.5 & $0.25-0.5$ \\
\hline $\begin{array}{l}\text { Magnesium, } \\
\mathrm{mEq} / \mathrm{kg} / \text { day }\end{array}$ & $0.25-0.5$ & 0.5 & 0.5 & 0.5 & $0.25-0.5$ \\
\hline $\begin{array}{l}\text { Phosphorus, } \\
\mathrm{mmol} / \mathrm{kg} / \text { day }\end{array}$ & $1-2$ & 1 & 0.8 & 0.6 & $0.25-0.5$ \\
\hline
\end{tabular}

7. Electrolytes $^{28}$

\begin{tabular}{|c|c|c|c|c|c|}
\hline & Neonates & 1 month-1 year & $1-3$ years & 4-10 years & $\begin{array}{c}\text { Older than } 10 \\
\text { years }\end{array}$ \\
\hline Sodium, $\mathrm{mEq} / \mathrm{kg} /$ day & $2-5$ & $3-4$ & $3-4$ & $2-3$ & $1-2$ \\
\hline Potassium, & $2-3$ & $2-3$ & $2-3$ & $2-3$ & $1-3$ \\
\hline
\end{tabular}

$\mathrm{mEq} / \mathrm{kg} /$ day

8. Vitamins - should include daily doses and are usually provided by parenteral multivitamin products, although some vitamins are available as individual parenteral products. Doses of individual vitamins dependent on age and weight. ${ }^{18,29,32,33}$

9. Trace Elements (TE) - should include daily doses and usually provided by parenteral multi-TE products, although many TE available as individual parenteral TE products. Doses of individual vitamins dependent on age and weight..$^{19,32}$

${ }^{a}$ These recommendations are not intended to supersede the judgment of the healthcare professional based on the circumstances of the individual patient.

PN, parenteral nutrition.

inability to obtain 1 of the products used in $\mathrm{PN}$, most commonly involving calcium gluconate, ILEs, multivitamins, sodium and potassium phosphate, and trace elements. One of every 4-5 respondents reported preventable adverse outcomes due to PN-related shortages. The common contributing factors to $\mathrm{PN}$ shortage-related errors included: ${ }^{54}$

- not making changes to protocols, templates, work labels, compounders, or order entry systems,

- mix-ups between electrolyte salts,

- confusion between pediatric and adult alternative products, and

- differences in concentration with alternative products.
Most, if not all, of these contributing factors (and potentially the associated errors) could be avoided with enhanced functionality of CDS within and interfaces between EHRs, ACDs, and pharmacy systems. Enhancements in the EHR could also improve communication to healthcare professionals regarding PN-related medication shortages. While PN-related medication shortages require a comprehensive management plan, a critical part of the plan must include enhanced functionality and optimization of EHRs, ACDs, and pharmacy systems. ${ }^{55,56}$ Potential advantages and functionality can include:

- reporting (e.g., prescribing and use data to guide the plan and target changes and/or education);

- blocking products that are not available; 
- directing prescribers to appropriate alternative products;

- using CDS (ideally at the time of order entry) to conduct automatic calculations of $\mathrm{PN}$ components in the background when using different products that have different components and/or different concentration of components;

- using CDS to calculate total amounts of ordered electrolytes from multiple components within the $\mathrm{PN}$; and

- educating and communicating with healthcare professionals regarding PN component and alternative product availability.

The ACD-EHR interface should transmit amounts of the calculated total ingredients, especially if electrolytes are ordered by their ions instead of by salts. ASPEN guidelines recommend salt-based ordering of electrolytes due to limitations of existing systems and EHRs to safely and appropriately calculate the final total ingredients in the PN admixture. ${ }^{6}$ Ion ordering is acceptable if the EHR can calculate and display the amounts of each electrolyte salt used to compound the PN admixture at the time of order entry, pharmacist verification, and on the label. Also, the EHR should be able to calculate and display the total amounts of electrolyte in the PN admixture, including electrolytes from the amino acid solutions as well as the ordered amounts of additional electrolytes. This is especially important when different amino acid solutions must be substituted during times of shortages.

Barcode scanning technology should be used when hanging and exchanging products used on ACDs and in compounding $P N$ admixtures. EHR vendors should collaborate with $A C D$ vendors and develop systems using a standardized format that will allow a direct electronic interface between any EHR and $A C D$ systems. The Health Level Seven (HL7) version $2 \mathrm{x}$ clinical messaging standards are used for transmitting data from the EHR to ancillary systems. Current HL7 version $2 \mathrm{x}$ standards (versioning changes with updates) have the ability to transmit patient information, insurance, diagnosis, allergies, orders for all clinical departments, results for tests ordered, and any updates of these data. ${ }^{57}$ Interfaces frequently are designed to take advantage of HL7 standards to improve the speed and accuracy with which systems can be integrated. ${ }^{58}$ Discussion with the HL7 Pharmacy Working Group concerning PN-specific content in evolving HL7 standards included the following suggestions: ${ }^{59}$

- complete a use case and an activity diagram which shows possible mechanism of the PN order,

- share ASPEN PN Safety Consensus Recommendations ${ }^{6}$ with HL7 Pharmacy Work Group,
- recommend additional work on PN orders within HL7 Standards, and

- share ASPEN PN Safety Consensus Recommendations ${ }^{6}$ with the Healthcare Information Management and Systems Society (HIMSS) EHR Association, the Office of the National Coordinator of Health IT, and other relevant EHR groups or alliances.

EHR-ACD interfaces should allow "versioning" to support PN order modification workflows (i.e., 1 order sent, then modified, most recent order should reflect changes). Currently HL7 allows for order versioning within common order segments via placer order numbers and order control field values. ${ }^{57} \mathrm{~A}$ message from the ACD to the EHR to indicate whether a bag has already been prepared for that day can allow for CDS to verify order modification and reduce provider calls or waste for less significant modifications. The ACD should have alerts noting the existence of a new version of a PN order to prevent queuing an outdated admixture for compounding or to prompt the user to locate and replace an already compounded bag. ACD vendors should also develop screens similar to those currently found in clinical nutrition management software. These ACD software screens should show all PN orders and changes placed for a patient during that admission in chronologic order and with placer order numbers.

Any modifications made to the PN order should be sent back to the provider for review and electronic signature. At minimum, EHR settings should be coded to require provider review when the order is placed. All PN order changes should be reviewed by a pharmacist. PN orders should be entered by a prescriber and reviewed and verified by a pharmacist within the EHR prior to order transmission to an ACD with a permanent record of the individual's name and the date and time of the order and order verification.

CDS should be used in both the EHR and the ACD. ${ }^{6}$ Ideally, CDS and evaluation of the PN order should first be completed within the EHR at the time of order entry and again at the time of order review and verification. If CDS is not available within the EHR, then CDS should be available and optimized within the ACD. The EHR and ACD should allow for setting soft-stop and hard-stop CDS alerts, limit alerts, and "best practice" alerts, and these should be configurable and customizable by the healthcare system pharmacy build team. ${ }^{6}$ CDS used in the EHR and ACD should be configurable to be complementary and compatible to reduce duplicative alerts and unnecessary rework. CDS used in the EHR and ACD should also be redundant when possible, in order to detect and prevent errors in interfacing and better support downtime. When it is not possible for CDS to reconcile the EHR and ACD 
alerts, the option for the incompatible CDS alerts to be disabled should be available.

Published data have demonstrated that using electronic systems and CDS can reduce the likelihood of errors. One systematic review suggested that most studies on HIT report positive effects on safety, quality, and efficiency. ${ }^{60}$ In addition, about $78 \%$ of studies on HIT reported some positive effects on safety for a wide range of medications in a variety of healthcare settings. CDS, including automatic dose-calculation features, resulted in a relative reduction in medication dosing errors by $37 \%-80 \%{ }^{60}$

CDS tools should be flexible enough to accommodate practice and resource differences between institutions. This flexibility should provide the correct CDS to the right user in the ordering workflow supported at the institution. Any unique warnings or alerts that may suggest a need to modify an order should be displayed at the time of ordering and decision making to prescribers authorized to order PN therapy.

The CDS should allow customization of soft-stop and hard-stop limits for component ingredients. Furthermore, CDS should include several features, including (but not limited to):

- dosing alerts (both upper and lower limits for clinical effectiveness and stability of the PN admixture) available in all possible units of measurement (e.g., amounts per day, amounts per dose, amounts per $\mathrm{kg}$ per day, amounts per $\mathrm{kg}$ per dose, amounts per volume [L], concentration [\%], etc.), taking into account whether the PN is being administered through a central or peripheral line;

- auto-populating fields (automatically pulling in information available in the system avoiding manual entry of this information);

- requiring mandatory fields to be completed before order entry;

- using checkboxes or drop-down menus instead of free text when possible; and

- using precipitation warnings for calcium and phosphorus based on the appropriate calcium-phosphate solubility curves for PN components ordered.

Unfortunately, adoption of EHRs and CDS to improve safety of the $\mathrm{PN}$ process has been limited. In recent surveys, only $33 \%-63 \%$ of respondents reported using an electronic order for PN and only 50\%-54\% utilized dosing guidelines and CDS built into the system. ${ }^{5,9}$ Furthermore, only about $28 \%$ of respondents reported that they had an automatic interface between the EHR and ACD at their institution. ${ }^{9}$

While the use of CDS can improve safety, alert fatigue (end users ignoring alerts after frequently being presented with clinically insignificant alerts) is a serious concern. Alert fatigue can be a potential barrier to successful adoption and optimization of CDS and can lead to undesirable outcomes. ${ }^{60}$ In 1 review of 17 studies, drug safety CDS alerts were overridden in $49 \%-96 \%$ of cases, and adverse events occurred in $2.3 \%-6 \%$ of overridden alert cases in the 3 studies that reported this additional data. ${ }^{61}$ Overriding an alert can be appropriate in some situations, but CDS alerts must be designed with high sensitivity and specificity to minimize alert fatigue and the need for overrides. ${ }^{61}$ Many factors can contribute to alert fatigue, starting with the design of the CDS alerts, all the way through implementation and end-user interpretation. CDS must be designed to minimize "false positives," "false negatives," and unclear alerts, all of which can lead to disruptions in workflow, alert fatigue, distrust of the system, excessive overrides, and unnecessary added workload, and ultimately result in adverse patient effects. ${ }^{61}$ Also, for maximal efficiency, whenever possible, CDS alerts should be configured so the alert is actionable, i.e., the end user can make appropriate changes to the order within the alert, avoiding multiple clicks to make the changes.

Tools should exist in the EHR and ACD to capture failed message transfers and support downtime of the automatic interface. An error message with a description of the error (ingredient mismatch, failed transmission, etc.) should display to relevant end users to communicate failed interface messages so that the error may be addressed. The option to resubmit a message to the ACD should also exist so that the message may be retransmitted following issue resolution. In the event of a longer downtime, the ability to produce a message and manually transfer this to the ACD should also exist.

EHRs should accommodate outsourcing of PN compounding without requiring manual transcription of the $P N$ orders. Some hospitals outsource the compounding of PN to an offsite, independent compounding pharmacy. Most of the time, the outsourced pharmacy is on a different electronic system than the hospital and may not even have access to the EHR used within the hospital, making it even more challenging to create a direct interface between the provider PN order entry and the ACD. This is similar to the concerns raised in issue number 5 below when transitioning PN patients from hospital to home or vice versa. These scenarios raise the issue of interoperability between different EHR systems and the importance of being able to transfer healthcare information, including complex orders, such as PN, safely, efficiently, and accurately between different healthcare organizations while minimizing the need for duplicative manual entry of ordering parameters.

\section{Ordering Cyclic PN, Taper Up, and Taper Down}

Most hospitalized patients receiving PN therapy receive continuous PN, but some patients require cyclic PN. Cyclic 
$\mathrm{PN}$ involves infusion of the PN over a certain number of hours per a 24-hour period of time and off $\mathrm{PN}$ the rest of that period of time. Cyclic PN may be used when a patient is being transitioned from PN to enteral or oral nutrition, preparation for transition to home $\mathrm{PN}$, or if continuing cyclic PN that the patient was receiving prior to hospitalizations. ${ }^{6,62}$ A 2010 review of the literature ${ }^{62}$ on the metabolic effects of cyclic PN infusion in adults and children revealed no significant differences in nitrogen balance or circulating counter regulatory hormones comparing patients on cyclic vs continuous PN infusion. Cyclic PN infusion may stabilize or improve elevated liver enzyme tests in patients who previously were receiving continuous PN infusion. ${ }^{62}$ Cyclic PN infusion was not associated with any significant increase in calcium, phosphorus, magnesium, or vitamin D losses. ${ }^{62}$ The ability to order cyclic PN should be included in the ordering functionality of all inpatient EHRs. Order parameters for cyclic PN should include the total volume of PN to infuse and the time period during which to infuse it, which can range from 8 hours to 20 hours with 12 hours being the most common infusion time period.

Cyclic PN can be ordered to abruptly start at the full rate at the beginning of the infusion and abruptly stop at the end of the infusion. Alternatively, the rate can be ordered to gradually taper up at the beginning of the infusion (taper up) and/or gradually taper down at the end of the infusion (taper down). Some PN infusion pumps, mostly ambulatory PN pumps, can automatically taper up and/or taper down the PN rate of infusion during the specified time period, usually 1-2 hours each, as well as calculate the rate to infuse the PN between the taper up and taper down periods in order to infuse the entire amount of PN ordered. If the PN infusion pump does not have this functionality, then the ordering provider will need to specify the taper up and taper down parameters as well as the rate throughout the middle of the infusion, and the caregiver will need to manually change the infusion rate at the specified periods of time to the specified infusion rates.

One study ${ }^{63}$ of 14 adult PN patients monitored blood samples every 5 minutes for 2 hours at the start of PN infusion without any taper up. The blood glucose level (BG) increased a mean of $60 \mathrm{mg} / \mathrm{dL}$ over the mean baseline of $127+76 \mathrm{mg} / \mathrm{dL}$. Patients with diabetes had a higher mean increase in BG compared with patients without diabetes (79 $+14 \mathrm{mg} / \mathrm{dL}$ vs $52+23 \mathrm{mg} / \mathrm{dL}$ ), but there was no correlation between the amount of rise in BG and either the baseline $\mathrm{BG}$ or the amount of glucose infused. The majority of the rise in BG occurred in the first 60 minutes, and there were no incidences of clinically significant hyperglycemia without the use of a taper up. However, in another study ${ }^{64}$ of 38 adult hospitalized PN patients being transitioned from continuous to cyclic PN in preparation for discharge to receive home $\mathrm{PN}, 18 \%$ of the patients developed severe hyperglycemia, i.e., BG greater than $250 \mathrm{mg} / \mathrm{dL}$, and in all of these patients, the severe hyperglycemia occurred when they were being switched from 16 hours a day to 12 hours a day. The authors recommended close monitoring of $\mathrm{BG}$ when transitioning from continuous to cyclic PN, especially in patients with end-stage liver failure, acute or chronic renal failure, insulin-dependent diabetes mellitus, or decompensated congestive heart failure.

A total of 86 adult patients from 4 studies ${ }^{63,65-67}$ who had their PN stopped abruptly with no taper down, showed transient decreases in BG, mainly within the first hour after stopping the $\mathrm{PN}$, with no patients experiencing symptomatic hypoglycemia. One randomized, controlled trial crossover study ${ }^{65}$ of 12 patients receiving cyclic PN, comparing taper down and no taper down, showed no significant differences between taper and no taper in the mean BG, insulin, epinephrine, norepinephrine, glucagon, growth hormone, or cortisol levels when checked before taper or abrupt discontinuation and every 15 minutes for 1.5 hours after discontinuation of PN.

Two studies ${ }^{68,69}$ have studied taper down in pediatric patients. One study ${ }^{68}$ included 14 pediatric PN patients ranging in age from 2.5-14 years, with a mean age of $8.0 \pm$ 3.5 years. After abrupt discontinuation of $\mathrm{PN}$, the mean $\mathrm{BG}$ level decreased from $117 \mathrm{mg} / \mathrm{dL}$ to $83 \mathrm{mg} / \mathrm{dL}$ at 15 minutes after discontinuation, with no further significant change at 30 minutes after discontinuation. Mean serum insulin levels were elevated prior to $\mathrm{PN}$ discontinuation and significantly dropped at 15 minutes after discontinuation, with only a small further decrease at 30 minutes after discontinuation. Only 1 patient developed hypoglycemia, i.e., BG less than $60 \mathrm{md} / \mathrm{dL}$, but this patient was on high-dose steroids and had a high glucose-to-insulin ratio prior to discontinuation of PN. No patients developed symptoms of hypoglycemia. The authors concluded that abrupt discontinuation of PN is safe in "most" children older than 2 years.

The second study ${ }^{69}$ involved 11 younger pediatric PN patients (mean age 12.3 months, range 1.5-36 months). After abrupt discontinuation of PN, $6(55 \%)$ of these patients developed hypoglycemia, defined as BG less than $40 \mathrm{mg} / \mathrm{dL}$, with stabilization of BG in these patients ranging from 15-45 minutes. Ten of the patients were studied again with a 1-hour taper down before PN discontinuation, and $2(20 \%)$ of these patients developed hypoglycemia. One of these patients also had developed hypoglycemia after abrupt discontinuation of PN, while the other did not. Of the 8 hypoglycemic episodes, in only 2 instances was there any clinical sign of hypoglycemia, which was manifested by sleepiness, and in only 1 instance was the hypoglycemia treated. Hypoglycemic episodes did not correlate with patient's age or glucose infusion rate. The authors concluded that due to a high incidence of hypoglycemia after abrupt discontinuation of $\mathrm{PN}$ in children less than 3 years, BG of these patients needs to be closely monitored at the time of PN discontinuation. Also, a 1-hour taper down did not 
completely avoid hypoglycemia, so a longer taper down period may be more beneficial.

The 2014 ASPEN Parenteral Nutrition Safety Consensus Recommendations ${ }^{6}$ noted that adult patients usually tolerate abrupt discontinuation of PN without significant risk of hypoglycemia but that many patients receiving home PN are frequently ordered a 30-minute to 60-minute taper-down period because most ambulatory PN infusion pumps can perform this function automatically. However, the ASPEN recommendations note that pediatric patients less than 3 years are more prone to hypoglycemia after abrupt discontinuation of $\mathrm{PN}$, and so require a taperdown period prior to $\mathrm{PN}$ discontinuation. The recommendations also call for close glucose monitoring at the beginning, during, and end of infusion when transitioning patients from continuous to cyclic $\mathrm{PN}$ with decrease in glucose monitoring once glycemic control has been established.

The number of steps in the taper varies from 1 step to multiple steps, and the time period of the taper varies from 30 minutes to 3 hours. So, all inpatient EHRs should have the functionality to order, document, and assist the caregiver in the performance of taper up and/or taper down of cyclic PN with a various number of steps in the taper and various length of time of the taper. EHRs should be able to accommodate at least the following regimens:

- Automatic infusion pump taper - These pumps will automatically taper the PN rate up or down during the time period specified as well as adjust the rate between taper periods to infuse the entire amount of PN ordered. Thus, the order needs to have the availability of a taper up and/or a taper down and each taper period needs to be able to be ordered in increments of 30 minutes in a range of 30 minutes to 3 hours.

- Manual taper - needs to have several different taperup and/or taper-down regimens available (Table 4) as well as a custom taper for patients that require other taper-up and/or taper-down options. Also, the EHR should calculate the rate that the PN should run between taper periods to infuse the entire amount of PN ordered. The rates of infusions during the different steps in the taper up and taper down should be called out on the MAR, and the EHR should have reminders in place for the nursing staff regarding when and how the rates need to be changed.

\section{Transition of PN From Hospital to Homel Alternative Care Setting and Vice Versa}

Approximately 40,000 individuals in the U.S. are dependent on home PN to sustain and improve their quality of life. ${ }^{70,71}$ Hospitalized patients receiving $\mathrm{PN}$ are sometimes discharged with continuation of $\mathrm{PN}$ in the home or alternate care setting (home $\mathrm{PN}$ ), and patients receiving home PN are frequently hospitalized, requiring continuation of the PN during hospitalization. These scenarios require transferring the PN orders back and forth between the hospital pharmacy (or outsourced pharmacy used by the hospital) and the pharmacy preparing the PN for the patient in the home/alternative care setting. This transition of PN orders has been challenging with many EHRs due to inability to electronically transfer orders between systems, resulting in ordering home PN on paper outside of the EHR or entering home PN orders into the hospital EHR from a home PN bag label or paper-faxed order from the home PN pharmacy. Both of these scenarios require manual transcription of the PN order and may involve transitioning between 2 $\mathrm{PN}$ order strategies with different component concentrations, dose units, etc., which increases the risk of misinterpretation of dosing, miscalculations, and transcription errors.

As HIT systems evolve, transmitting a $\mathrm{PN}$ order to the receiving entity (hospital pharmacy to home/alternative care setting pharmacy or vice versa) electronically without the need for manual transcription is essential for patient safety and to decrease potential errors. Integrating PN recommendations into evolving HIT standards will be critical to supporting consistent, standardized PN orders, including providing complete $\mathrm{PN}$ orders as patients move across healthcare settings. In the U.S., transitions of care guidelines are driven by requirements of interoperability ${ }^{72}$ via the Office of the National Coordinator (ONC) for HIT Certification Program ${ }^{73}$ and the Improving Medicare PostAcute Care Transformation (IMPACT) Act of 2014. ${ }^{74}$ The IMPACT Act points to the HL7 Consolidated Clinical Document Architecture R2.1 HIT standard for electronic transitions of care guidance. While there are multiple standards which allow for including PN orders across care settings, it is critical for PN orders to be included in HIT standards guidance via the latest version of the ONC Interoperability Standards Certification (at publication, the 2015 Edition Health IT Certification Criteria) $)^{75}$ and also to evolving HIT standards via the ONC Interoperability Standards Advisory (at publication, 2017 Final Interoperability Standards Advisory). ${ }^{76}$

EHR systems must have the functionality to allow the provider to quickly and easily review the last PN orders within the EHR from the hospital, enter any modifications to the PN orders needed for home PN, and send these home PN orders to the home infusion company in a clear, concise, and standardized fashion that is compatible with the recommended PN ordering and labeling standards and guidelines. Similar functionality should be available when ordering a PN admixture during hospitalization based on a previous home $\mathrm{PN}$ order. 
Table 4. Different Manual Taper-Up and Taper-Down Regimens That Should Be Available Within the EHR. ${ }^{\mathrm{a}}$

\begin{tabular}{|c|c|c|c|c|}
\hline \multirow[b]{2}{*}{ Taper Regimens } & \multicolumn{2}{|c|}{ Taper Up } & \multicolumn{2}{|c|}{ Taper Down } \\
\hline & Time period & Rate adjustment & Time period & Rate adjustment \\
\hline 1 hour/1 step & $\begin{array}{l}\text { - } \\
\text { - } 1 \text { hourt Infusion } \\
\text { infusion }\end{array}$ & $\begin{array}{l}\text { - } 1 / 2 \text { full rate } \\
\text { Full rate }+ \text { differ- } \\
\text { ence to make up } \\
\text { for taper }\end{array}$ & $\begin{array}{l}\text { - } 1 \text { hour prior to end } \\
\text { of infusion } \\
\text { - End of infusion }\end{array}$ & $\begin{array}{ll}\text { - } & 1 / 2 \text { full rate } \\
\text { - } & \text { Stop infusion }\end{array}$ \\
\hline 1 hour/2 step & $\begin{array}{l}\text { - } \text { Start Infusion } \\
\text { - } 30 \text { minutes after } \\
\text { start infusion } \\
\text { - } 1 \text { hour after start }\end{array}$ & $\begin{array}{l}\text { - } 1 / 3 \text { full rate } \\
\text { - } 2 / 3 \text { full rate } \\
\text { - } \quad \text { Full rate }+ \text { differ- } \\
\text { ence to make up } \\
\text { for taper }\end{array}$ & $\begin{array}{l}\text { - } 1 \text { hour prior to end } \\
\text { of infusion } \\
\text { - } 30 \text { minutes prior } \\
\text { to end of infusion } \\
\text { - End of infusion }\end{array}$ & $\begin{array}{ll}\text { - } & 2 / 3 \text { full rate } \\
\text { - } & 1 / 3 \text { full rate } \\
\text { - } & \text { Stop infusion }\end{array}$ \\
\hline 2 hour $/ 2$ step & $\begin{array}{l}\text { - } \text { Start Infusion } \\
\text { - } 1 \text { hour after start } \\
\text { infusion } \\
\text { - } 2 \text { hours after start }\end{array}$ & $\begin{array}{l}\text { - } 1 / 3 \text { full rate } \\
\text { - } 2 / 3 \text { full rate } \\
\text { - } \text { Full rate }+ \text { differ- } \\
\text { ence to make up } \\
\text { for taper }\end{array}$ & $\begin{array}{l}\text { - } 2 \text { hours prior to } \\
\text { end of infusion } \\
\text { - } 1 \text { hour prior to end } \\
\text { of infusion } \\
\text { - End of infusion }\end{array}$ & $\begin{array}{ll}\text { - } & 2 / 3 \text { full rate } \\
\text { - } & 1 / 3 \text { full rate } \\
\text { - } & \text { Stop infusion }\end{array}$ \\
\hline
\end{tabular}

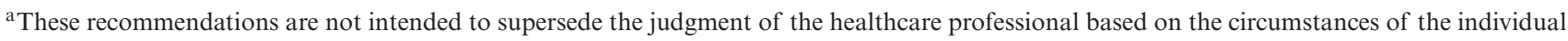
patient. EHR, electronic health record.

\section{Summary}

Ordering and managing PN therapy using EHRs is a complex and multistep process that involves multiple clinicians from multiple, different specialties. This consensus statement serves to identify the best practices to date for electronic ordering of PN using HIT. As HIT standards become more prevalent in the infrastructure of health systems, these best practices need to be integrated into evolving and mature HIT standards, and the incorporation of these standards into work practices, policy, and design/build of EHR technology should result in safer processes for ordering, administering, and managing PN therapy. EHRs should include the following PN therapy functionalities:

1. Use standardized and validated PN order and labeling templates as recommended by ASPEN (see Figures 1-7).

2. Design PN orders to facilitate ordering based on ASPEN recommendations and incorporate CDS to guide the prescriber on requirements and maximal limits for macronutrients and micronutrient for adult, pediatric, and neonatal patients.

3. Analyze workflow from patient-specific PN ordering to administration to the patient and documentation of delivered $\mathrm{PN}$ admixtures in such a way as to minimize manual human transcription or double documentation and provide appropriate CDS support in all of these steps.
4. Include the functionality to order cyclic $\mathrm{PN}$ with and without taper up and/or taper down.

5. Include the functionality to transition from hospital $\mathrm{PN}$ orders to home $\mathrm{PN}$ orders and vice versa.

Many of the current EHRs do not incorporate 1 or more of the above in their build and/or workflow. EHR vendors need to recognize these deficiencies and actively pursue the clinical nutrition expertise to enhance and optimize these areas. Nutrition-support clinicians need to engage EHR vendors, the healthcare system EHR build team, and the medical and administrative leadership within their healthcare system to be involved in the process of purchasing, building, training, implementing, and optimizing their EHR to promote inclusion of the above functionalities within the PN therapy workflow. These steps will result in significant improvement in safety for patients receiving PN therapy. Optimization of the EHR and CDS does not replace the requirement that the clinicians and caregivers involved in the PN workflow must be adequately educated, trained, and experienced in PN therapy.

\section{References}

1. Ayers P, Guenter P, Holcombe B, Plogsted S. How to prescribe parenteral nutrition therapy. In: Ayers P, Guenter P, Holcombe B, Plogsted S, eds. ASPEN Parenteral Nutrition Handbook, 2nd ed. Silver Spring, MD: American Society for Parenteral and Enteral Nutrition; 2014:111-134

2. National Inpatient Sample (NIS) of the Healthcare Cost and Utilization Project (HCUP) from the Agency for Healthcare Research and Quality (AHRQ). http://hcupnet.ahrq.gov/. Accessed December 10, 2015. 
3. Institute for Safe Medication Practices. 2016-2017 Medication Safety Best Practices for Hospitals. http://www.ismp.org/tools/ bestpractices/TMSBP-for-Hospitals.pdf. Accessed January 2017.

4. Worthington $\mathrm{P}$, Balint $\mathrm{J}$, Bechtold $\mathrm{M}$, et al. When is parenteral nutrition appropriate? JPEN J Parenter Enteral Nutr. 2017;41:324-377.

5. Boullata JL, Guenter P, Mirtallo JM. A parenteral nutrition use survey with gap analysis. JPEN J Parenter Enteral Nutr. 2013;37:212-222.

6. Ayers P, Adams S, Boullata JL, et al. ASPEN parenteral nutrition safety consensus recommendations. JPEN J Parenter Enteral Nutr. 2014;38:296-333.

7. Boullata JI, Gilbert K, Sacks G, et al. American Society for Parenteral and Enteral Nutrition. ASPEN clinical guidelines: parenteral nutrition ordering, order review, compounding, labeling, and dispensing. JPEN J Parenter Enteral Nutr. 2014;38(3):334-377.

8. Kochevar M, Guenter P, Holcombe B. ASPEN statement on parenteral nutrition standardization. JPEN J Parenter Enteral Nutr. 2007;31:441448.

9. Vanek VW, Ayers P, Kraft M, et al. Follow-up survey on functionality of nutrition documentation and ordering nutrition therapy in currently available electronic health record (EHR) systems. Nutr Clin Pract. 2016;31:401-415.

10. Mirtallo J, Canada T, Johnson D, et al. ASPEN Board of Directors and Task Force for the Revision of Safe Practices for Parenteral Nutrition. Safe practices for parenteral nutrition [published correction appears in JPEN J Parenter Enteral Nutr. 2006;30:177]. JPEN J Parenter Enteral Nutr. 2004;28:S39-S70

11. Agency for Healthcare Research and Quality. Standardized ordering and administration of total parenteral nutrition reduces errors in children's hospital. https://innovations.ahrq.gov/profiles/standardizedordering-and-administration-total-parenteral-nutrition-reduceserrors. Accessed April 11, 2016.

12. Ayers P, Guenter P, Holcombe B, Plogsted S. Review and verification of parenteral nutrition orders, preparing parenteral nutrition formulations, and labeling. In: Ayers P, Guenter P, Holcombe B, Plogsted S, eds. ASPEN Parenteral Nutrition Handbook, 2nd ed., Silver Spring, MD: American Society for Parenteral and Enteral Nutrition; 2014:135163.

13. Sacks GS. Safety surrounding parenteral nutrition systems. JPEN $J$ Parenter Enteral Nutr. 2012;36(2 Suppl.):20S-22S.

14. Boullata JI. Overview of the parenteral nutrition use process. JPEN $J$ Parenter Enteral Nutr. 2012;36(2 Suppl.):10S-13S.

15. Singer P, Berger MM, Van den Berghe G, et al. ESPEN. espen guidelines on parenteral nutrition: intensive care. Clin Nutr. 2009;28(4):387400 .

16. Braga M, Ljungqvist $\mathrm{O}$, Soeters $\mathrm{P}$, Fearon K, Weimann A, Bozzetti F; ESPEN. ESPEN guidelines on parenteral nutrition: surgery. Clin Nutr. 2009;28(4):378-386.

17. Fat Emulsion: Drug Information. Lexicomp Online ${ }^{\circledR}$. https://online. lexi.com. Accessed December 2015 through UpToDate.

18. Vanek VW, Borum P, Buchman A, et al. Novel Nutrient Task Force, Parenteral Multi-Vitamin and Multi-Trace Element Working Group; American Society for Parenteral and Enteral Nutrition (ASPEN) Board of Directors. ASPEN position paper: recommendations for changes in commercially available parenteral multivitamin and multi-trace element products. Nutr Clin Pract. 2012;27(4):440491.

19. Vanek VW, Borum P, Buchman A, et al; Novel Nutrient Task Force, Parenteral Vitamin and Trace Element Working Group and the American Society for Parenteral and Enteral Nutrition (ASPEN): A call to action to bring safer parenteral micronutrient products to the U.S. market. Nutr Clin Pract. 2015;30(4):559-569.

20. Driscoll DF, Bhargava HN, Li L, Zaim RH, Babayan VK, Bistrian BR. Physicochemical stability of total nutrient admixtures. Am J Health Syst Pharm. 1995;52(6):623-634.
21. Gervasio J. Total nutrient admixtures (3-in-1): pros vs cons for adults. Nutr Clin Pract. 2015;30(3):331-335.

22. Mirtallo JM, Dasta JF, Kleinschmidt KC, Varon J. State of the art review: intravenous fat emulsions: current applications, safety profile, and clinical implications. Ann Pharmacother. 2010;44:688-700.

23. Driscoll DF. Lipid injectable emulsions: 2006. Nutr Clin Pract. 2006;21:381-386

24. Trissel LA. Phosphates. Trissel's ${ }^{\mathrm{TM}} 2$ clinical pharmaceutics database. Cashiers, NC: TriPharma Communications. https://www. micromedexsolutions.com. Accessed January 2016.

25. Kraft MD, Btaiche IF, Sacks GS, Kudsk KA. Treatment of electrolyte disorders in adult patients in the intensive care unit. Am J Health Syst Pharm. 2005;62(16):1663-1682.

26. Potassium chloride: drug information. Lexicomp Online ${ }^{\circledR}$. https://online.lexi.com. Accessed December 2015 through UpToDate.

27. Pittiruti M, Hamilton H, Biffi R, MacFie J, Pertkiewicz M; ESPEN. ESPEN guidelines on parenteral nutrition: central venous catheters (access, care, diagnosis and therapy of complications). Clin Nutr. 2009;28(4):365-377.

28. ASPEN Board of Directors and the Clinical Guidelines Task Force. Guidelines for the use of parenteral and enteral nutrition in adult and pediatric patients. JPEN J Parenter Enteral Nutr. 2002;26(1 Suppl.):1SA-138SA.

29. Sathe MN, Patel AS. Update in pediatrics: focus on fat-soluble vitamins. Nutr Clin Pract. 2010;25(4):340-346.

30. Koletzko B, Goulet O, Hunt J, et al. Guidelines on Paediatric Parenteral Nutrition of the European Society of Paediatric Gastroenterology, Hepatology and Nutrition (ESPGHAN) and the European Society of Clinical Nutrition and Metabolism (EPSEN), supported by the European Society of Paediatric Research (ESPR). J Pediatr Gastroenterol Nutr. 2005;41(Suppl. 2):S19-S27.

31. Holliday MA, Segar WE. The maintenance need for water in parenteral fluid therapy. Pediatrics. 1957;19:823-832.

32. Greene HL, Hambidge KM, Schanler R, Tsang RC. Guidelines for the use of vitamins, trace elements, calcium, magnesium, and phosphorus in infants and children receiving total parenteral nutrition: report of the Subcommittee on Pediatric Parenteral Nutrient Requirements from the Committee on Clinical Practice Issues of the American Society for Clinical Nutrition. Am J Clin Nutr. 1988;48(5):1324-1342.

33. Koo W, Christie J, Saba M, Lulic-Botica M, Warren L. Water-soluble essential micronutrients. In: Corkins MR, ed. ASPEN Pediatric Nutrition Support Core Curriculum, 2nd ed. Silver Spring, MD: ASPEN; 2015:69-90.

34. Dudrick SJ. Rhoads lecture: a 45-year obsession and passionate pursuit of optimal nutrition support: puppies, pediatrics, surgery, geriatrics, home TPN, ASPEN, et cetera. JPEN J Parenter Enteral Nutr. 2005;29(4):272-287.

35. Wilmore DW, Dudrick SJ. Growth and development of an infant receiving all nutrients exclusively by vein. JAMA. 1968;203(10):860864.

36. Dudrick SJ, Wilmore DW, Vars HM, Rhoads JE. Long-term total parenteral nutrition with growth, development, and positive nitrogen balance. Surgery. 1968;64(1):134-142.

37. Driscoll DF. Pharmaceutical and clinical aspects of lipid injectable emulsions JPEN J Parenter Enteral Nutr. 2017;41:125-134.

38. Allwood MC, Kearney MC. Compatibility and stability of additives in parenteral nutrition admixtures. Nutrition. 1998;14(9):697-706.

39. Sacks GS, Rough S, Kudsk KA. Frequency and severity of harm of medication errors related to the parenteral nutrition process in a large university teaching hospital. Pharmacotherapy. 2009;29:966-974.

40. Bonnabry P, Cingria L, Sadeghipour F, Ing H, Fonzo-Christe C, Pfister RE. Use of a systematic risk analysis method to improve safety in the production of paediatric parenteral nutrition solutions. Qual Saf Health Care 2005;14:93-98. 
41. Brown CL, Garrison NA, Hutchinson AA. Error reduction when prescribing neonatal parenteral nutrition. Am J Perinatol. 2007;24:417427.

42. American Society of Health-System Pharmacists. ASHP guidelines on the safe use of automated compounding devices for the preparation of parenteral nutrition admixtures. Am J Health-Syst Pharm. 2000;57:1343-1348.

43. MacKay M, Anderson C, Boehme S, Cash J, Zobell J. Frequency and severity of parenteral nutrition errors at a large children's hospital after implementation of electronic ordering and compounding. Nutr Clin Pract. 2016; 31:195-206.

44. Hilmas E, Peoples JD. Parenteral nutrition prescribing processes using computerized prescriber order entry: Opportunities to improve safety. JPEN J Parenter Enteral Nutr. 2012;36 (Suppl. 2):32S-35S.

45. Institute for Safe Medication Practices. Another tragic parenteral nutrition compounding error. ISMP Medication Safety Alert! April 21, 2011. https://www.ismp.org/newsletters/ acutecare/articles/20110421.asp. Accessed May 12, 2016.

46. Institute for Safe Medication Practices. Mismatched prescribing and pharmacy templates for parenteral nutrition (PN) lead to data entry errors. ISMP Medication Safety Alert! June 28, 2012. https://www.ismp.org/newsletters/acutecare/showarticle.aspx?id=25. Accessed April 11, 2016.

47. FDA. First Annual Report on Drug Shortages for Calendar Year 2013. http://www.fda.gov/downloads/drugs/drugsafety/drugshortages/ ucm384892.pdf. Accessed May 12, 2016.

48. U.S. Food and Drug Administration. Drug shortages infographic. http://wayback.archive-it.org/7993/20170111082354/http://www.fda. gov/downloads/Drugs/DrugSafety/DrugShortages/UCM384892.pdf. Updated December 15, 2016. Accessed March 27, 2018.

49. Staes C, Jacobs J, Mayer J, et al. Description of outbreaks of healthcare-associated infections related to compounding pharmacies, 200012. Am J Health-Syst Pharm. 2013;70:1301-1312.

50. Davis C, Javid PJ, Horslen S. Selenium deficiency in pediatric patients with intestinal failure as a consequence of drug shortage. JPEN J Parenter Enteral Nutr. 2014;38:115-118.

51. Pramyothin P, Kim DW, Young LS, et al. Anemia and leukopenia in a long-term parenteral nutrition patient during a shortage of parenteral trace element products in the United States. JPEN J Parenter Enteral Nutr. 2013;37:425-429.

52. Robbins R. "Children are dying". The Washingtonian, May 22, 2013. www.washingtonian.com/articles/people/children-are-dying/index.php. Accessed Jan 1, 2016.

53. Institute for Safe Medication Practices. Drug shortages: national survey reveals high level of frustration, low level of safety. ISMP Medication Safety Alert 2010;15(15):Sept 23.

54. Institute for Safe Medication Practices. Survey links PN component shortages to adverse outcomes. ISMP Medication Safety Alert 2014;19(3):Feb 13

55. Wright L, Grisso AG, Feldott CC, et al. Using computerized prescriber order entry to implement actions of the pharmacy and therapeutics committee. Hosp Pharm. 2007;42:763-766.

56. Hassig TB, McKinzie TB, Fortier CR, et al. Clinical management strategies and implications for parenteral nutrition shortages in adult patients. Pharmacother. 2014;34:72-84.

57. Health Level Seven International. HL7 Messaging Standard Version 2.8.2. http://www.hl7.org/implement/standards/product_brief.cfm?pro duct_id=403. Accessed April 25, 2017.

58. Chaffee BW, Bonasso J. Strategies for pharmacy integration and pharmacy information system interfaces, part 2: scope of work and technical aspects of interfaces. Am J Health-Syst Pharm. 2004;61(5):506-514.
59. Health Level Seven (HL7) Pharmacy Working Group. Attach 7.06 PN in EHRs Pharmacy WG Meeting. January 11, 2016. http://www.hl7.org/Special/committees/medication/minutes.cfm. Accessed March 27, 2018.

60. Jones SS, Rudin RS, Perry T, Shekelle PG. Health information technology: an updated systematic review with a focus on meaningful use. Ann Intern Med. 2014;160:48-64.

61. Van der Sijs H, Aarts J, Vulto A, Berg M. Overriding of prescribing alerts in computerized physician order entry. $J$ Am Med Inform Assoc. 2006;13:138-147.

62. Stout SM, Cober MP. Metabolic effects of cyclic parenteral nutrition infusion in adults and children. Nutr Clin Pract. 2010;25(3):277-281.

63. Krzywda EA, Andris DA, Whipple JK, et al. Glucose response to abrupt initiation and discontinuation of total parenteral nutrition. JPEN J Parenter Enteral Nutr. 1993;17(1):64-67.

64. Suryadevara S, Celestin J, DeChicco R, Austhof S, Corrigan M, Speerhas R, Steiger E. Type and prevalence of adverse events during the parenteral nutrition cycling process in patients being prepared for discharge. Nutr Clin Pract. 2012;27(2):268-273.

65. Eisenberg PG, Gianino S, Clutter WE, Fleshman JW. Abrupt discontinuation of cycled parenteral nutrition is safe. Dis Colon Rectum. 1995;38(9):933-939.

66. Wagman LD, Newsome HH, Miller KB, Thomas RB, Weir GC. The effect of acute discontinuation of total parenteral nutrition. Ann Surg. 1986;204(5):524-529.

67. Nirula R, Yamada K, Waxman K. The effect of abrupt cessation of total parenteral nutrition on serum glucose: a randomized trial. $\mathrm{Am}$ Surg. 2000;66(9):866-869.

68. Werlin SL, Wyatt D, Camitta B. Effect of abrupt discontinuation of high glucose infusion rates during parenteral nutrition. $J$ Pediatr. 1994;124(3):441-444.

69. Bendorf K, Friesen CA, Roberts CC. Glucose response to discontinuation of parenteral nutrition in patients less than 3 years of age. JPEN J Parenter Enteral Nutr. 1996;20(2):120-122.

70. Ireton-Jones C, DeLegge M. Home parenteral nutrition registry: a fiveyear retrospective evaluation of outcomes of patients receiving home parenteral nutrition support. Nutrition. 2005;21(2):156-160.

71. Howard L. Home parenteral nutrition: survival, cost, and quality of life. Gastroenterology. 2006;130(2 Suppl. 1):S52-S59.

72. Office of the National Coordinator of Health IT Website: A shared nationwide interoperability roadmap. https://www.healthit.gov/policyresearchers-implementers/interoperability. Accessed November 21, 2016.

73. Office of the National Coordinator of Health IT Website: ONC Health IT Certification Program. https://www.healthit.gov/policy-researchersimplementers/about-onc-health-it-certification-program. Accessed November 21, 2016.

74. Centers for Medicare and Medicaid Services. IMPACT Act of 2014 Data Standardization \& Cross Setting Measures. https://www.cms.gov/Medicare/Quality-Initiatives-Patient-Assess ment-Instruments/Post-Acute-Care-Quality-Initiatives/IMPACTAct-of-2014/IMPACT-Act-of-2014-Data-Standardization-and-CrossSetting-MeasuresMeasures.html. Updated September 14, 2016 Accessed March 27, 2018.

75. Office of the National Coordinator of Health IT Website: 2015 Edition Health IT Standards Criteria. https://www.healthit.gov/policyresearchers-implementers/2015-edition-final-rule. Accessed November 21, 2016.

76. Office of the National Coordinator of Health IT Website: 2017 Interoperability Standards Advisory. https://www.healthit.gov/isa/. Accessed April 25, 2017. 